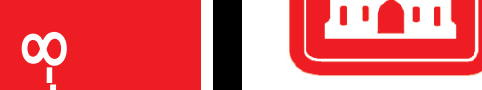

US Army Corps of Engineers $s_{\circledast}$ Engineer Research and Development Center

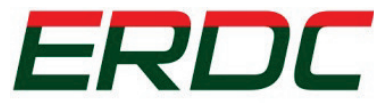

INNOVATIVE SOLUTIONS for a safer, better world

Aquatic Plant Control Research Program

\title{
SAVEWS Jr. User's Manual, Version 1.0
}

Bruce Sabol, Eddie Melton, Deborah Shafer, Jessie Jarvis,

April 2014

Steve Evert, and Richard Loyd 
The US Army Engineer Research and Development Center (ERDC) solves the nation's toughest engineering and environmental challenges. ERDC develops innovative solutions in civil and military engineering, geospatial sciences, water resources, and environmental sciences for the Army, the Department of Defense, civilian agencies, and our nation's public good. Find out more at www.erdc.usace.army.mil.

To search for other technical reports published by ERDC, visit the ERDC online library at http://acwc.sdp.sirsi.net/client/default. 


\title{
SAVEWS Jr. User's Manual, Version 1.0
}

\author{
Bruce Sabol and Deborah Shafer \\ Environmental Laboratory \\ US Army Engineer Research and Development Center \\ 3909 Halls Ferry Road \\ Vicksburg, MS 39180-6199 \\ Eddie Melton \\ JAYA Corporation \\ 4845 University Square, Suite 9 \\ Huntsville, AL 35816 \\ Jessie Jarvis and Steve Evert \\ Richard Stockton College \\ 101 Vera King Ferris Drive \\ Galloway, NJ 08205-9441 \\ Richard Loyd \\ US Army Engineer District, New England \\ 696 Virginia Road \\ Concord, MA 01742-2718 \\ Final report \\ Approved for public release; distribution is unlimited.
}

\author{
Prepared for US Army Corps of Engineers \\ Washington, DC 20314-1000
}




\section{Abstract}

This user's manual describes components, assembly, system configuration, data collection procedures, and data processing activities for the second iteration of the Submersed Aquatic Vegetation (SAV) Early Warning System (SAVEWS Jr.). SAVEWS Jr. uses two frequencies (200- and $800-\mathrm{kHz}$ ) from a downward-aimed echo sounder to determine the bottom depth and presence/absence of SAV. If SAV is present, canopy height and vegetation percent coverage are estimated. Once collected, the digital data (Lowrance proprietary .SL2 files) are displayed, using the SAVEWS Jr. software. Users then select a configuration file that is appropriate to the environment sampled. A general version of this file is provided with the installation software to serve as a starting point for users to develop their own customized files.

After initial processing, a display of classified output (bottom depth and canopy top) is superimposed on the colorized echogram and aligned with data plots of canopy height and percent coverage. Beyond quality assurance graphics, the primary output of SAVEWS Jr. is the .SDF file (SAVEWS data file) which is an ASCII, comma-delimited file containing position-referenced classified output. This can be used directly in statistical analyses or mapping software.

DISCLAIMER: The contents of this report are not to be used for advertising, publication, or promotional purposes. Citation of trade names does not constitute an official endorsement or approval of the use of such commercial products. All product names and trademarks cited are the property of their respective owners. The findings of this report are not to be construed as an official Department of the Army position unless so designated by other authorized documents. 


\section{Contents}

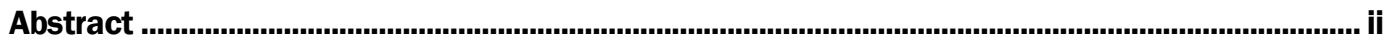

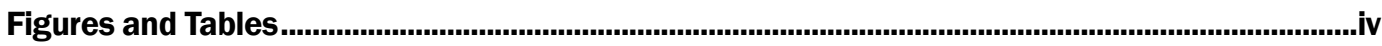

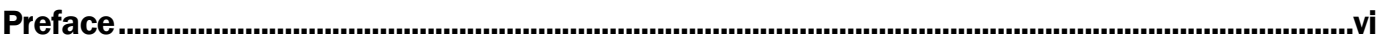

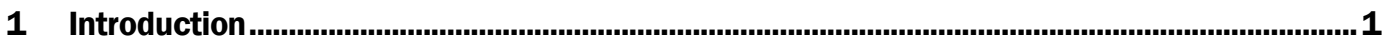

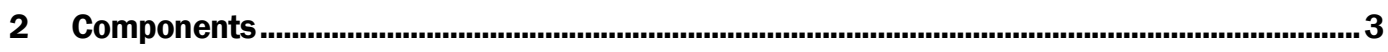

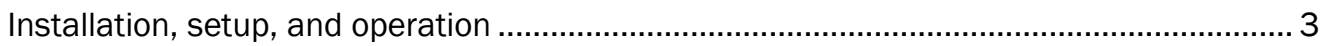

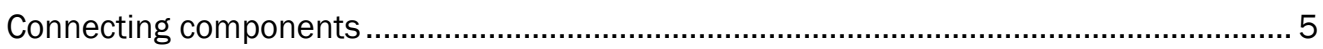

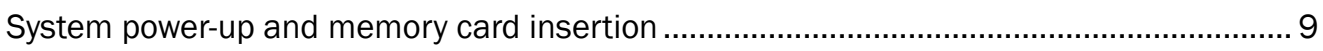

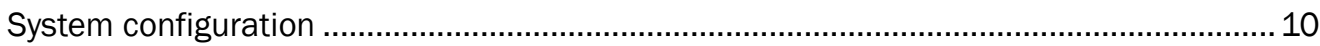

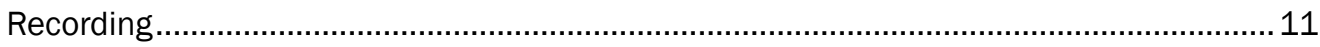

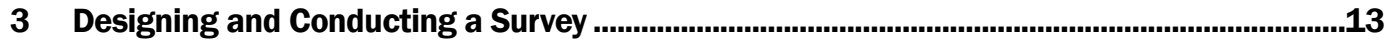

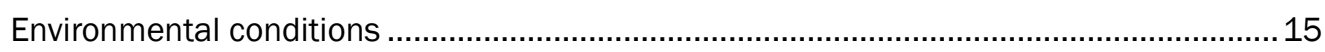

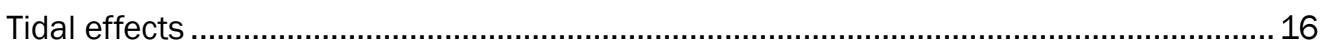

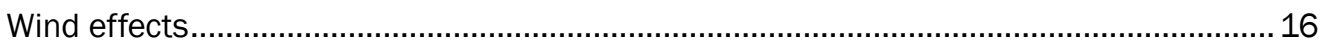

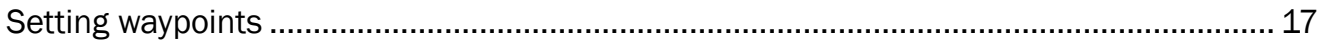

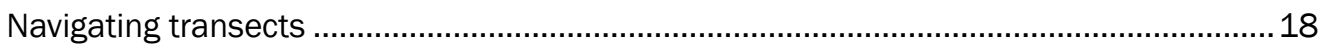

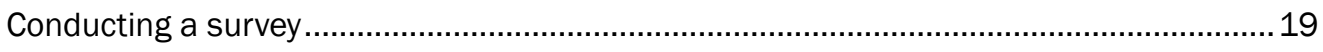

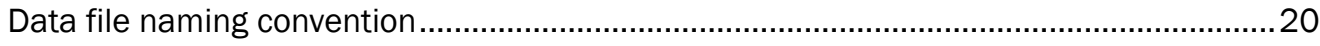

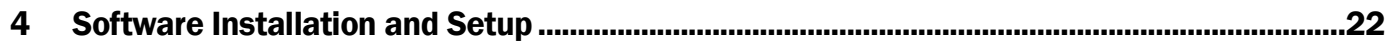

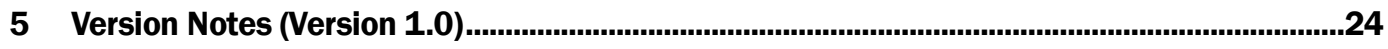

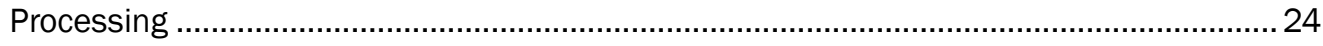

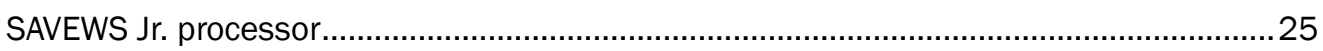

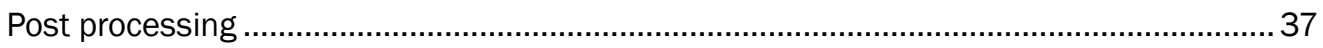

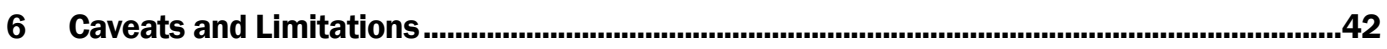

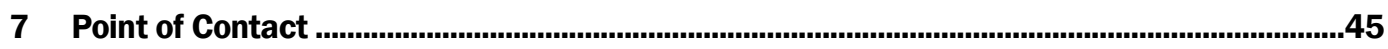

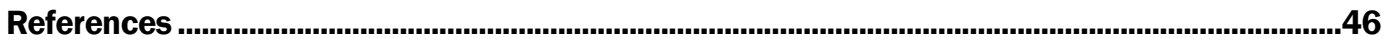

Appendix A: Assembling a Self-Contained SAVEWS Jr. Field Unit .........................................47

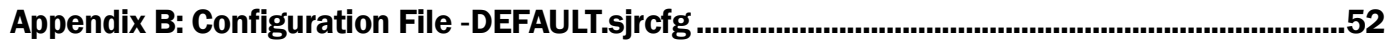

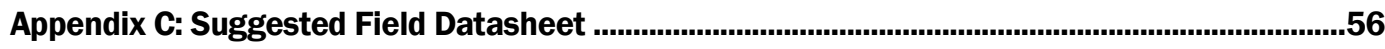

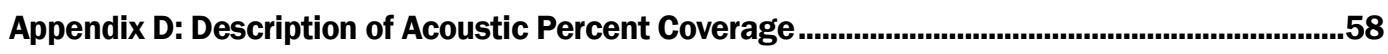

Report Documentation Page 


\section{Figures and Tables}

\section{Figures}

Figure 1. Lowrance HDS-10 console and 200-kHz skimmer transducer............................................ 4

Figure 2. StructureScan sonar and transducer..................................................................................... 4

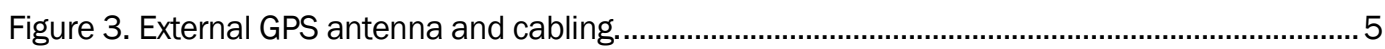

Figure 4. Connecting power to HDS console. ...................................................................................... 6

Figure 5. Connecting skimmer transducer cable to HDS console........................................................ 6

Figure 6. Connecting power to LSS-2 sonar module......................................................................

Figure 7. StructureScan power cabling; note connected yellow wires. ...................................................

Figure 8. Structure Scan transducer cabling.................................................................................... 8

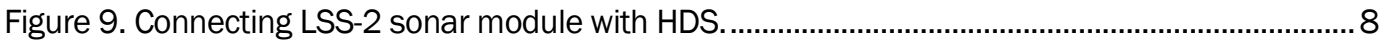

Figure 10. Connecting external GPS to HDS.................................................................................

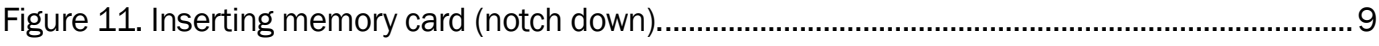

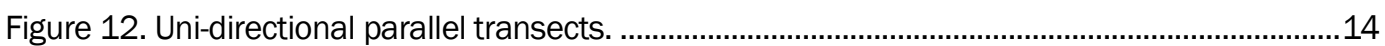

Figure 13. Bi-directional parallel transects are surveyed in opposing directions. .............................15

Figure 14. Colorized echogram of acoustic transect at Cuttyhunk Harbor, MA. ...............................26

Figure 15. SAVEWS_Jr data processing window, Generate output image is on by default. ..............27

Figure 16. Processing GUI filled in and ready to start program......................................................2

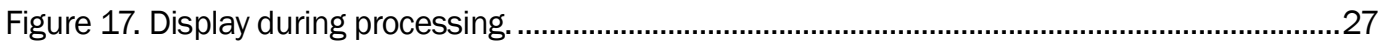

Figure 18. Graphic of processed output generated from a non-optimized CF

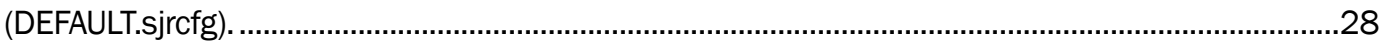

Figure 19. Raw output file (.SDF); a. processing parameters, and b. processed data......................29

Figure 20. Reprocessing file 20120626_134202 with usernoise=160.........................................32

Figure 21. Colorized echogram of acoustic transect of Eurasian watermilfoil in northern

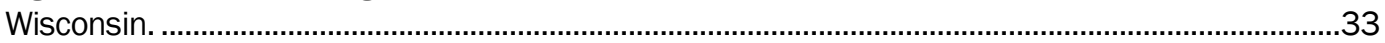

Figure 22. Processed output generated from a non-optimized CF (DEFAULT.sjrcfg)........................34

Figure 23. First reprocessing file 20110902_145734 (usernoise=115, startdepth=0.3) designed to improve vegetation detection performance.

Figure 24. Second reprocessing file 20110902_145734 (bot_change_tol $=0.10 \mathrm{~m}$ )

designed to smooth erratic bottom depth declarations.

Figure 25. Tide data file must contain integer month and day, decimal hours local time, and tide ( $\mathrm{ft}$ ).

Figure 26. The list file must contain SDF filenames, in date_time format, transect ID \#, depth of transducer face $(\mathrm{m})$, and replicate \#.

Figure 27. Waypoint file for computing location along transect..........................................................38

Figure 28. FINALIZE graphic user interface window after executing program....................................40

Figure 29. Example output of FINALIZE program (Output.CSV).......................................................... 41

Figure A1. Portable SAVEWS Jr. System............................................................................................48 
Figure A2. LSS-2, 12-V power source and wiring. .........................................................................48

Figure A3. Quick disconnect mount external connections. ..............................................................49

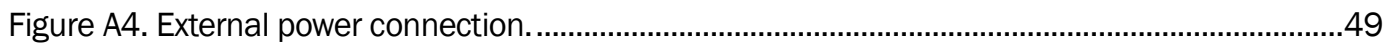

Figure A5. Transducers, mounted on pivot arm, and GPS antenna mounting bracket....................50

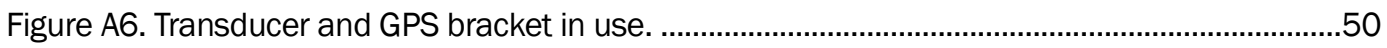

Figure D1. Acoustic survey cartoon and computation of outputs using 10 pings per report cycle. .59

Figure D2. Hypothetical comparison of diver and acoustic measurements for a 2.5-m linear segment of SAV. 60

Figure D3. Comparison of interpreted underwater videography and SAVEWS acoustic system in a mixed seagrass bed in southwest Florida. 61

\section{Tables}

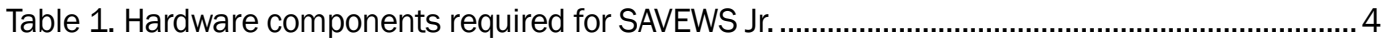

Table 2. Definition of output variables form raw output file (.SDF) . ..................................................30

Table 3. Definition of output variables from FINALIZE program........................................................... 41

Table A1. Components of example self-contained SAVEWS Jr. system .............................................51 


\section{Preface}

The work reported herein was conducted as part of the Aquatic Plant Control Research Program (APCRP). The APCRP is sponsored by Headquarters, US Army Corps of Engineers (HQUSACE), and is assigned to the US Army Engineer Research and Development Center (ERDC) under the purview of the Environmental Laboratory (EL), Vicksburg, Mississippi. The APCRP is managed under the Civil Works Environmental Engineering and Sciences Office, Dr. Alfred F. Cofrancesco, Technical Director. Dr. Linda S. Nelson is Program Manager of the APCRP.

The Principal Investigator for this work was Bruce M. Sabol, Environmental Systems Branch (ESB), Ecosystem Evaluation and Engineering Division (EEED), US Army Engineer Research and Development Center - Environmental Laboratory (EL). This work was performed under the general supervision of Dr. Beth Fleming, Director, EL; Dr. Jack Davis, Deputy Director, EL; Edmond Russo, Chief, EPED; and Mark Graves, Chief, ESB.

COL Jeffrey R. Eckstein was the Commander and Executive Director of ERDC, and Dr. Jeffery P. Holland was Director. 


\section{Introduction}

Automated processing of digital echo sounder data has proven to be useful for depth and canopy characterization in beds of submersed aquatic vegetation (SAV). The first version of this capability, SAVEWS (Submersed Aquatic Vegetation Early Warning System), released in 2001 (Sabol et al. 2002), required an expensive calibrated scientific echo sounder that was beyond the financial means of many resource agencies. Consequently, the system was underutilized by agencies that would have benefited from SAVEWS data. Since then, consumer-grade marine electronics have advanced to the point they have many of the same features as the high-cost scientific echo sounders for a fraction of the cost. The low-cost marine electronics market was surveyed and a widely used echo sounder/GPS system (HDS- $x$, Lowrance Electronics, Tulsa, Oklahoma) with digital recording capability was selected as a good candidate for automated processing. This system is designated as SAVEWS Jr. The primary difference between SAVEWS Jr. and the previous SAVEWS code is that the low-cost systems are not calibrated and simultaneously use two different frequencies. This necessitated a fundamentally different approach to the processing. The signal processing code developed was necessarily written around the data formats and characteristics of the Lowrance HDS system. Selection of this system does not constitute endorsement by the government. Potentially, other vendors' equipment could also be used although required code modification may be significant. The current version of the processing software is written in MatLab to facilitate rapid code development, at the expense of slightly slower execution times. As the code matures, the final version of MatLab will either be optimized for faster execution or it will be rewritten in a different language. These modifications will correspond to subsequent software releases beyond Version 1.o.

This user's manual describes components, assembly, system configuration, data collection procedures, and data processing. The goal is to make this a stand-alone technology that can be operated by scientists and field personnel involved with SAV mapping. The system uses two frequencies (200- and 800-kHz) from a downward-aimed echo sounder. The frequencies are processed to determine the bottom depth and presence/ absence of SAV. If SAV is present, the frequencies are used to estimate the canopy height and vegetation percent coverage. The key to processing 
acoustic data for SAV is to correctly locate the bottom, particularly when SAV is present. Using two frequencies resulted in better bottom tracking relative to the earlier one-frequency SAVEWS. Once collected, the digital data (Lowrance proprietary .SL2 files) are displayed, using the SAVEWS Jr. software. The user will then select a configuration file that is appropriate to the environment sampled. This file will set a host of algorithm parameter values used within the software. A general version of this file is provided with the installation software. This will serve as a starting point for users to develop their own customized files. The installation software also provides some examples of how configuration files are set; the authors of this report can provide assistance in developing these files in particularly difficult cases.

After initial processing, a display of classified output (bottom depth and canopy top) is superimposed on the colorized echogram for review by the user. This is aligned with data plots of canopy height and percent coverage. The user then ascertains whether these outputs reasonably represent conditions evident in the colorized echogram file. If not, the file can be rerun after selecting different configuration values. Beyond quality assurance graphics, the primary output is the .SDF file (SAVEWS data file) which is an ASCII, comma-delimited file containing position-referenced classified output. This can be used directly in statistical analyses or mapping software. 


\section{Components}

Required components for the SAVEWS Jr. system are listed in Table 1 and illustrated in Figures 1-3. All except the external Global Positioning System (GPS) and its supporting network cable are mandatory. This set of components allows a relatively wide-beam, 200-kHz and the narrow-beam downlooking $800-\mathrm{kHz}$ (or $455 \mathrm{-kHz}$ ) signal to be simultaneously collected. The HDS system has an internal GPS but the external GPS provides greater positional accuracy and data rate, and allows the antenna to be positioned independent of the HDS system. This makes it possible to position the GPS antenna directly over the transducer and to more precisely navigate planned transects since the output rate is five times as fast, resulting in less lag in navigation guidance.

\section{Installation, setup, and operation}

Brief instructions for equipment setup are provided. Users are encouraged to download and read detailed installation and setup instructions available for each recommended component from the Lowrance website (www.Lowrance.com/en/Downloads/Manuals/). Transom mounting, as suggested in the Lowrance manual, is very convenient because the transducers are permanently affixed to the boat and the only thing needed to conduct a survey is a fresh SDHC data card. However, two problems can be created with this technique: 1) the side lobe of the Structure Scan can "see" the lower unit of the outboard motor, if not trimmed properly, creating an artifact in the recorded data, and 2) the two transducers are not laterally aligned; therefore, they sample different bottom areas during data collection. If not yet installed, users are encouraged to consider another mounting technique, such as the transducer mount system illustrated in Figure A5, mounted on the bow. Instructions for assembling the entire system in a self-contained field-portable container, ideal for rapid deployment to any boat, are contained in Appendix A. The advantage of the self-contained unit is that assembly or connection will not be required each time the system is used. 
Table 1. Hardware components required for SAVEWS Jr.

\begin{tabular}{|l|l|l|l|l|}
\hline Component & Description & Part \#A & CostB & Note \\
\hline $\begin{array}{l}\text { Echo sounder } \\
\text { with internal } \\
\text { GPS system }\end{array}$ & $\begin{array}{l}\text { Lowrance HDS-10 (or HDS-7 or 8 with } \\
\text { smaller screen and lower cost) with } \\
\text { 200-KHz (20-deg) skimmer transducer with } \\
\text { built-in temperature sensor }\end{array}$ & $000-0140-00$ & $\$ 2,500$ & $\begin{array}{l}\text { Available from } \\
\text { multiple } \\
\text { sources }\end{array}$ \\
\hline SDHC cards & 8 GBytes & & & If not on PC \\
\hline $\begin{array}{l}\text { External SDHC } \\
\text { card reader }\end{array}$ & & & & \\
\hline $\begin{array}{l}\text { Side scan } \\
\text { transducer }\end{array}$ & $\begin{array}{l}\text { Lowrance 132-06 StructureScan Sonar } \\
\text { option for HDS with 455- and 800-KHz } \\
\text { transducers }\end{array}$ & LSS-2 & $\$ 600$ & \\
\hline External GPS & $\begin{array}{l}\text { Lowrance high-sensitivity GPS receiver } \\
\text { antenna with N2K cable and T connectors }\end{array}$ & $\begin{array}{l}\text { LGC-4000-CE } \\
(000-0125-28)\end{array}$ & $\$ 200$ & \\
\hline
\end{tabular}

A. http://store.navico.com part numbers B. Approximate cost as of May 2012.

Figure 1. Lowrance HDS-10 console and 200-kHz skimmer transducer.

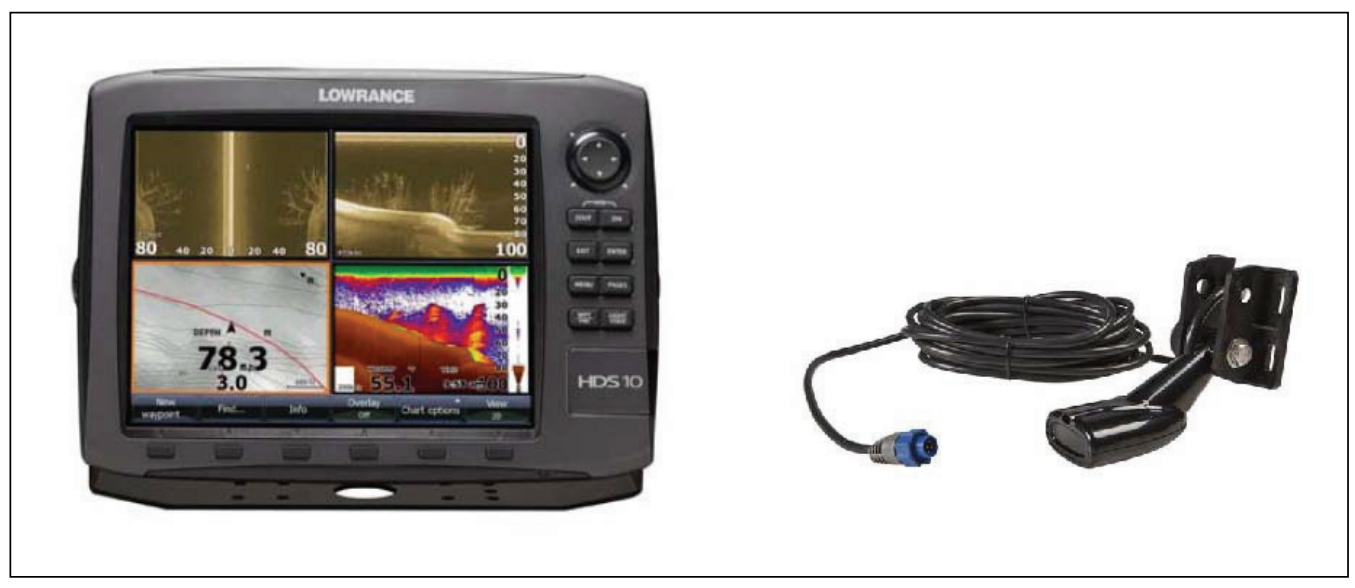

Figure 2. StructureScan Sonar and transducer.

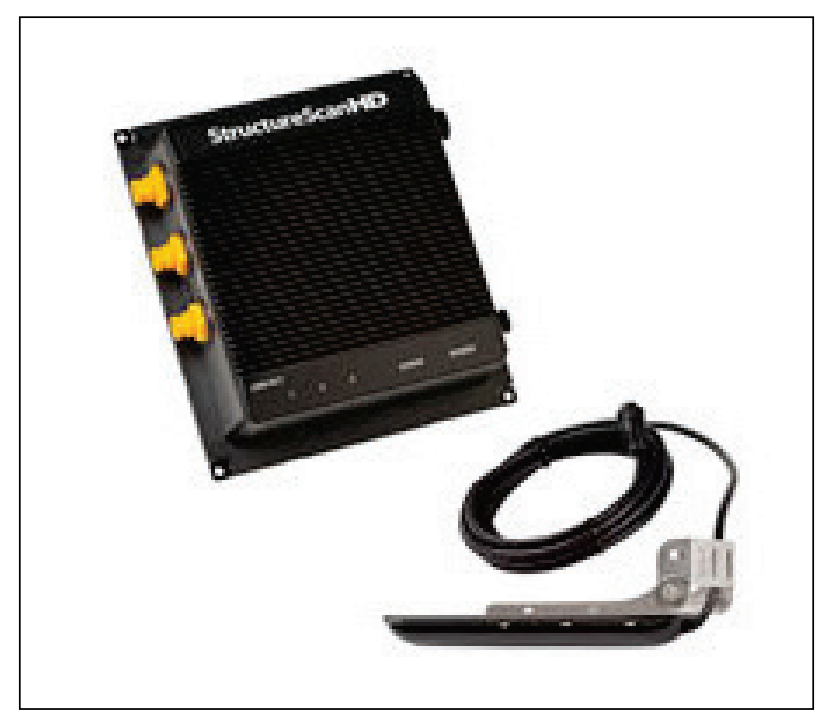


Figure 3. External GPS antenna and cabling.

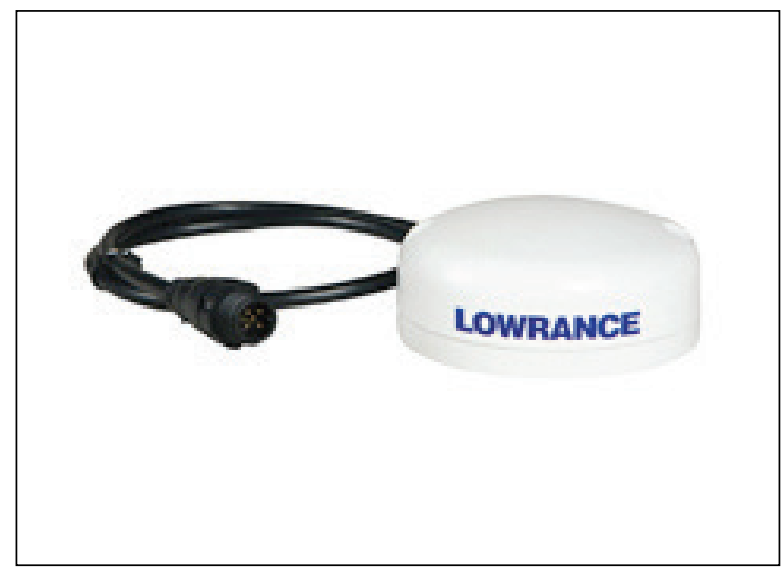

\section{Connecting components}

The process for connecting components is as follows:

1. Connect the HDS power cable to the blue PWR/DATA plug on the back of the HDS (Figure 4) and a $+12-\mathrm{V}$ battery. Cigarette lighter connectors should be avoided, as they can easily lose connection, requiring that the entire system be reset.

2. Connect the skimmer transducer cable to the blue SONAR plug on the back of the HDS (Figure 5).

3. Connect the StructureScan power cable to the $12-\mathrm{V}$ source and to the black POWER plug on the back of the LSS-2 Sonar module (Figure 6). Make sure that the yellow wire on the StructureScan power cable at the battery is connected to the yellow wire on the HDS power cable at the battery (Figure 7). This will allow the StructureScan to be turned on with the main HDS power button.

4. Connect the StructureScan transducer cable to the black SONAR plug on the back of the LSS-2 Sonar module (Figure 8).

5. Connect the communication link between the LSS-2 Sonar module and the HDS. The cable with the yellow plugs gets connected to ENET port \#1 on the LSS-2 module and the yellow ENET plug on the back of the HDS (Figure 9).

6. Connect the pre-configured GPS network cable (see Lowrance NMEA 2000 Network Installation Instructions [www.lowrance.com/Downloads/Manuals]) to the GPS antenna and to the black NMEA 2K plug on the back of the HDS (Figure 10).

7. Attach the power connections on the pre-configured GPS network cable to the battery. 
8. System components are now correctly connected. Before proceeding to the next step (power up and configuration), submerge the transducers in water. While this step is not required by Lowrance, it is a generally recommended practice to protect hydroacoustic transducers from damage.

Figure 4. Connecting power to HDS console.

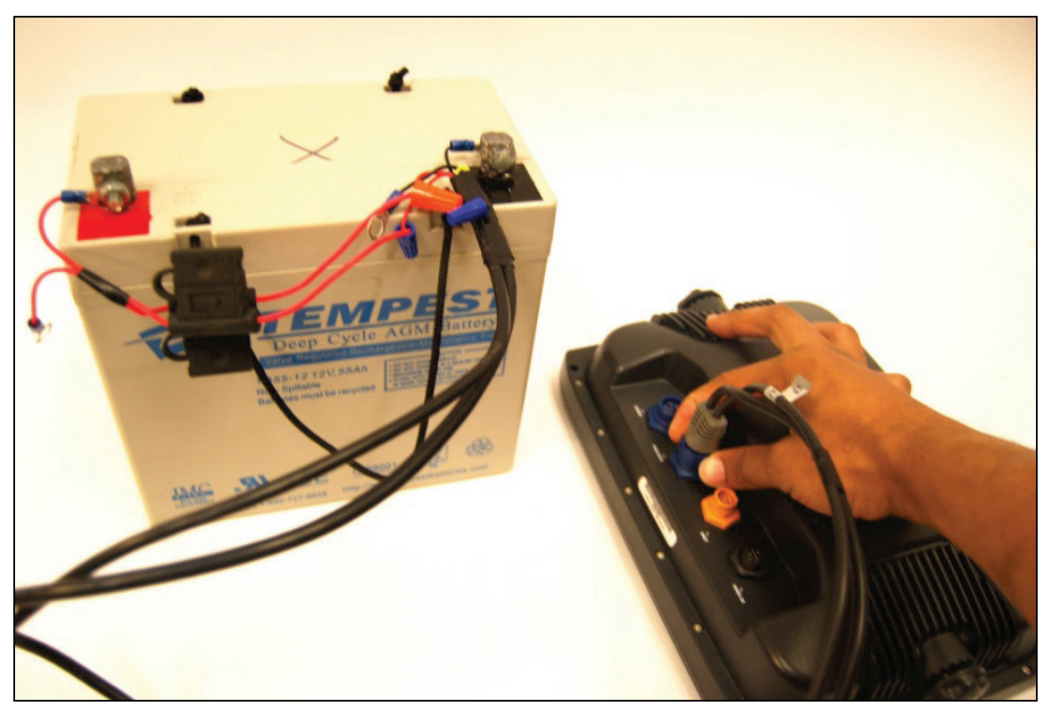

Figure 5. Connecting skimmer transducer cable to HDS console.

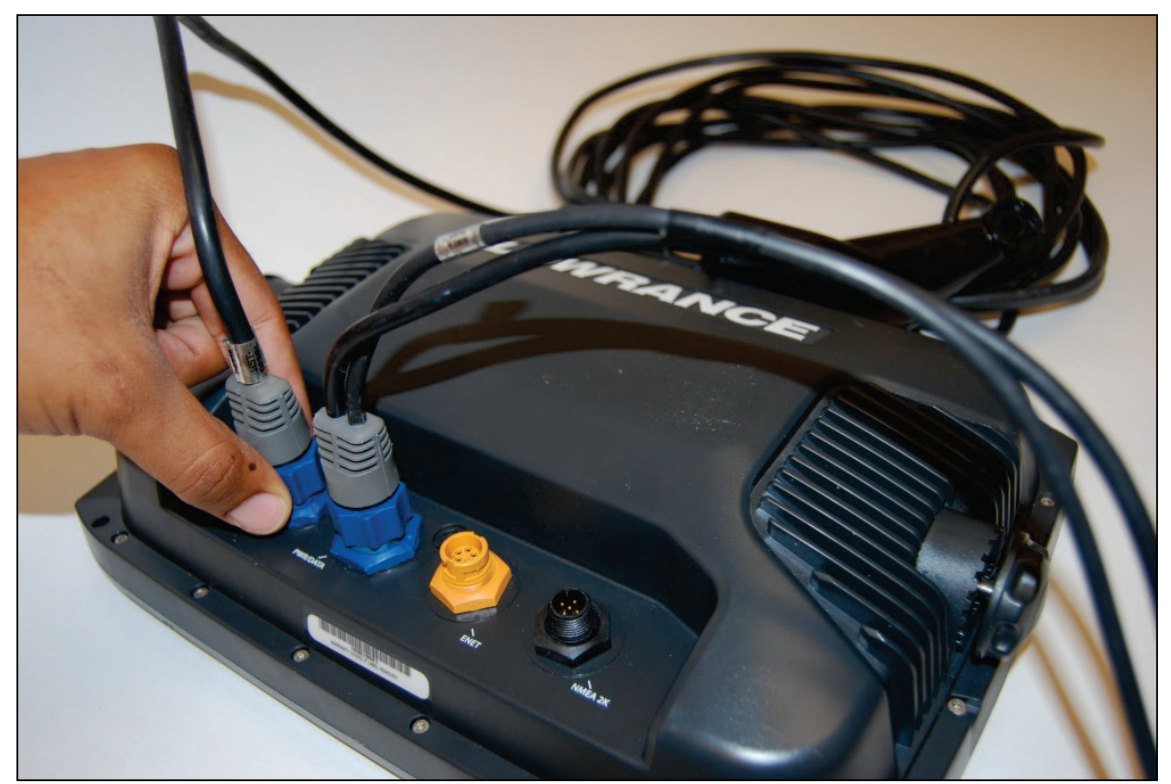


Figure 6. Connecting power to LSS-2 Sonar module.

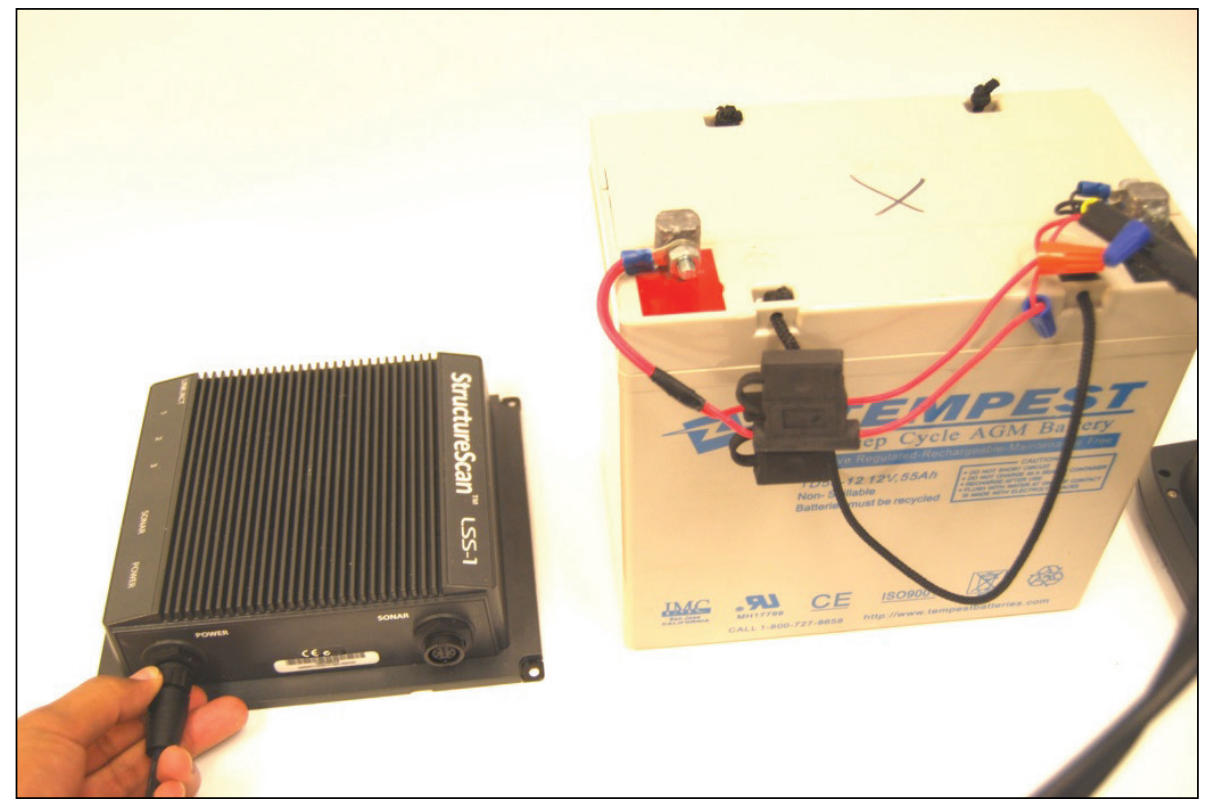

Figure 7. StructureScan power cabling; note connected yellow wires.

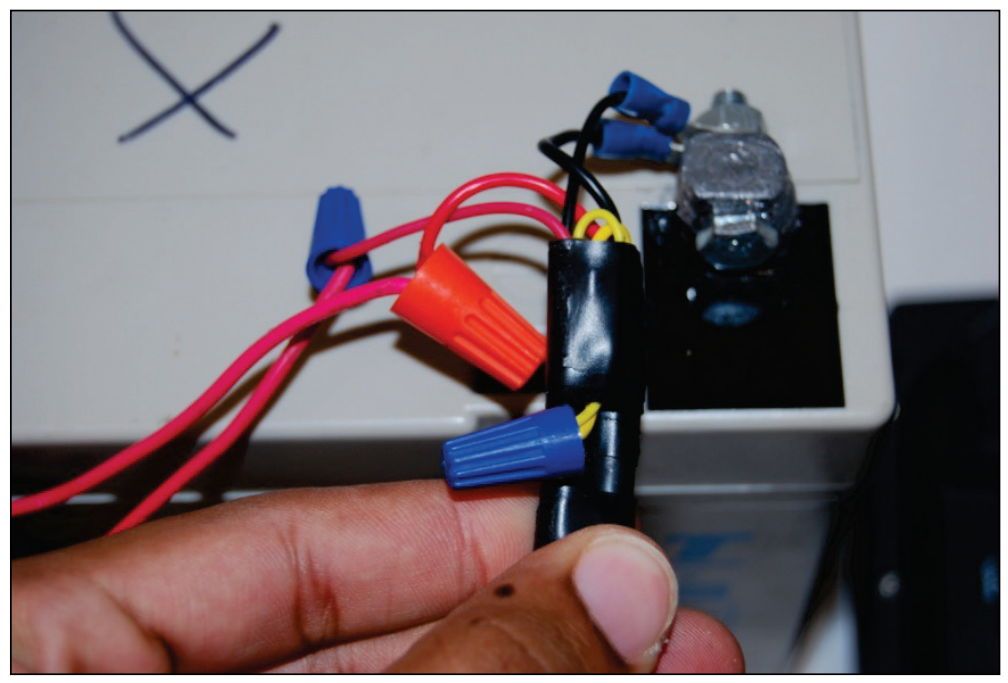


Figure 8. Structure Scan transducer cabling.

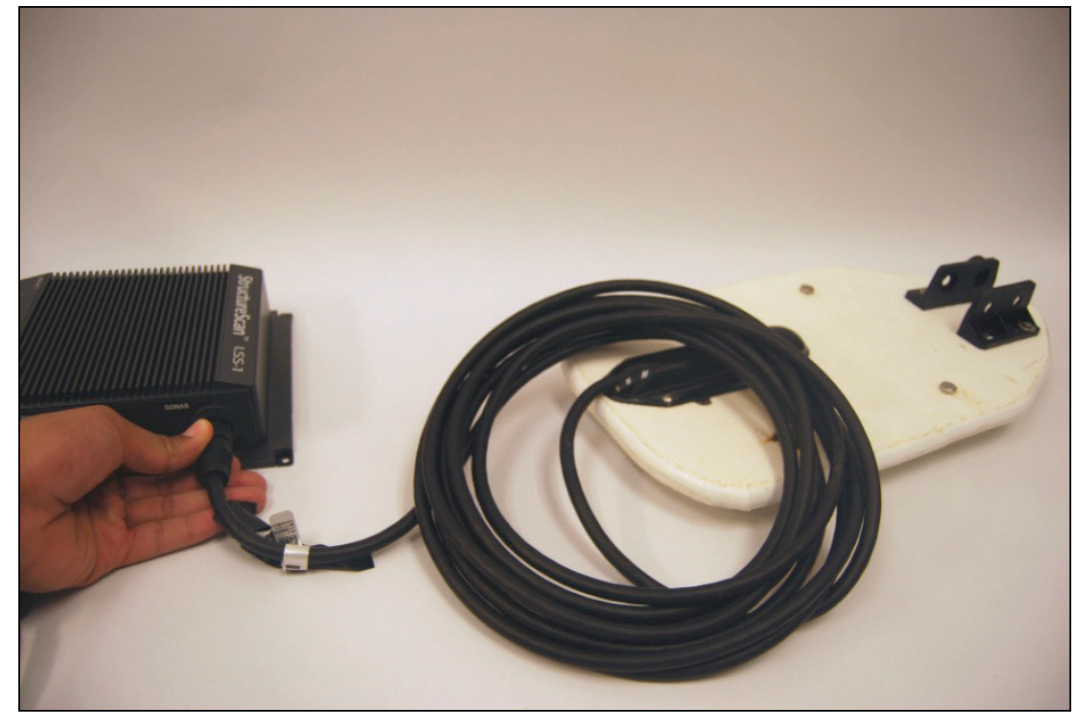

Figure 9. Connecting LSS-2 Sonar module with HDS.

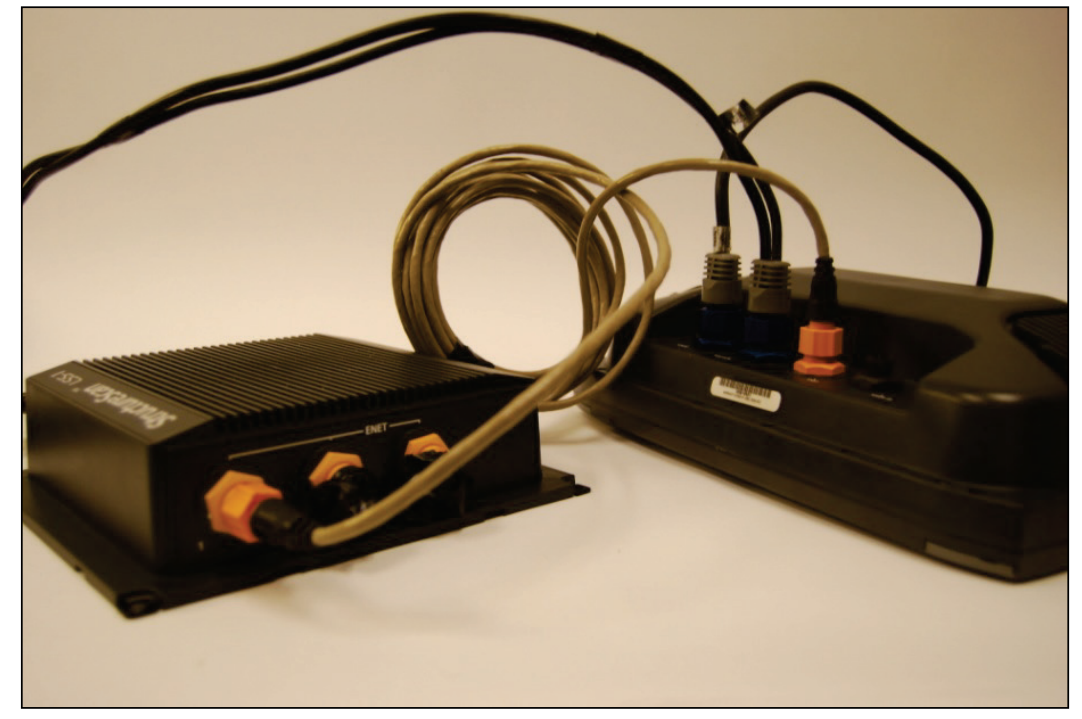


Figure 10. Connecting external GPS to HDS.

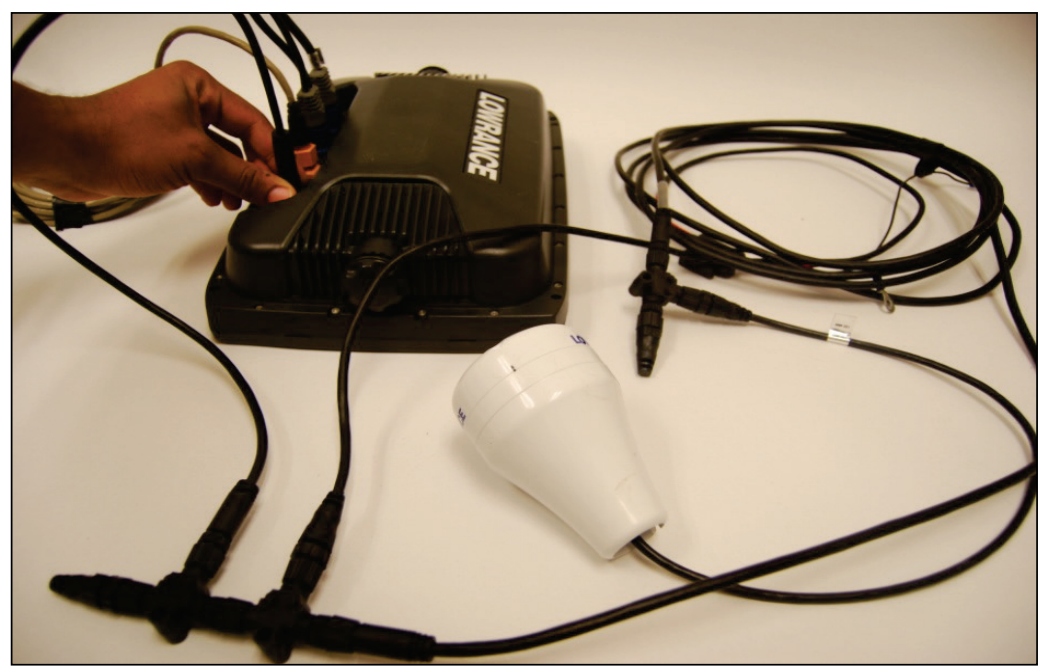

\section{System power-up and memory card insertion}

The processes for power-up and memory card insertion are outlined below. Numbering of these steps continues from the previous section.

9. The HDS console is used to configure the system for use (Figure 1).

10. Power on the HDS by pressing the LIGHT/POWER button on the lower right corner of the HDS front.

11. Dismiss the warning (button on bottom row under "Accept").

12. Insert one or more SDHC memory cards into the slots under the door at lower right of HDS front (Figure 11).

Figure 11. Inserting memory card (notch down).

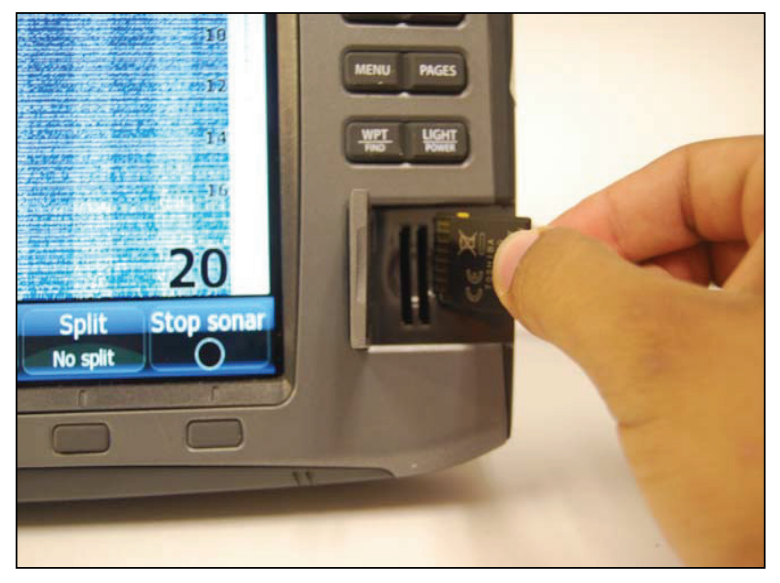

Card \#1 goes on the right and card \#2 goes on left, with notch side down.

13. Press "Pages" button on right side of HDS face.

14. Use multi-directional pad to page over to "Waypoints, routes, trails," then move to "Files."

a. Press Enter button on right side of HDS.

b. Make sure the memory card(s) is recognized by HDS. Card listings will be at the top of the screen. If a card is not listed, eject and reinsert until HDS recognizes the card.

15. Press Exit on the right side of the HDS. Memory card(s) are now inserted and ready to receive data. 


\section{System configuration}

200-kHz transducer. Configuration of the 200-kHz transducer is described below. Numbering of these steps continues from the previous section.

16. Press "Page," then scroll over to top heading "Sonar," then down to subheading "Sonar," and press Enter. Sonar echogram display will be activated.

17. Press Menu (right side of HDS).

a. Set "Range" to maximum depth expected in survey (system actually records to twice user-set depth), do not use Auto Range for recording.

b. Set "Frequency" to $200 \mathrm{KHz}$.

c. Set "Ping Speed" to 10.

d. Click (press Enter) at "Sonar Options."

i. Fish ID - off.

ii. Fish ID beeps - disabled (circle not filled in).

iii. Click "Exit" to return to Sonar window.

e. Click on "Settings" at bottom of menu.

i. Press Enter.

ii. Go to "Sonar," (press Enter) and configure as follows:

1) Network Sonar - enabled (circle filled in).

2) Noise Rejection - off.

3) Surface Clarity - off.

4) Manual Mode - enabled (circle filled in).

5) Fishing Mode - general use.

18. Press "Exit" twice.

19. Verify that Sonar is in operation (data scrolling); if not scrolling, make sure "Stop Sonar" is not highlighted. Transducer configuration is now complete.

StructureScan transducer. Configuration of the StructureScan transducer is described below. Numbering of these steps continues from the previous section.

20. Press "Pages" button on right side of HDS face

21. Use multi-directional pad to page over to "Structure," then down to "Structure and Sonar," and press Enter. Verify that the sidescan echogram 
is on and scrolling on the screen. If it is not, make sure SONAR STOP (from Menu) has not been activated. If still no scrolling, recheck cabling and battery power.

22. Press Menu, then configure as follows:

a. Set RANGE to expected maximum depth (do not use Auto Range for recording).

b. Set FREQUENCY to $800 \mathrm{kHz}$.

c. Set VIEW to Down.

d. Press Structure options, then configure as follows:

i. Set Structure surface clarity to OFF.

ii. Set Structure noise rejection to OFF.

iii. Press EXIT twice to return to data screen.

23. Configuration complete, press Exit on right side of HDS

External GPS. Configuration of the external GPS is described below. Numbering of these steps continues from the previous section.

24. On the HDS panel, press MENU, then SETTINGS, then NETWORK, then Device List to verify that HDS recognizes external GPS (LGC400o High Sensitivity Antenna). If LGC 4000 is not listed on the device list, recheck connections, then EXIT.

25. Go to MENU/SETTINGS/NETWORK/DATA SOURCE SELECTION/GPS (right arrow)/ALL DATA (right arrow). Highlight either AUTO (selects strongest GPS signal between internal and external GPS), or LGC400o (uses ONLY external antenna). Then press SELECT followed by CLOSE.

26. GPS output and healthy status can be seen by going to: MENU/SETTINGS/SYSTEM/SATELLITES.

27. Suggest positioning the GPS antenna directly over the StructureScan transducer.

\section{Recording}

The recording process is outlined in the section that follows. Numbering of these steps continues from the previous section.

28. To begin recording:

a. Press "Menu."

b. Go to "Log Sonar," press Enter. 
c. Set up recording session (HDS will reset options if the steps are not followed in this order).

i. Choose save location (Memory card 1 or 2, NOT Internal).

ii. Set "Bytes per sounding" to 3200 (algorithm response to lower data rates is currently being investigated, but version 1.0 requires the full 3200 bytes per sounding).

iii. Select "Log all channels." This will record the 200-kHz skimmer, and all three channels of the StructureScan transducer (left, right, and down), using the frequency selected in step 22b). An .sl2 file will be generated. It is acceptable to use the default file names offered by the HDS system - SONARxxxx. These file names will need to be renamed, using a date/time format as described later, before processing is done (see section titled Data File Naming Convention).

iv. Press Record to begin the recording session.

v. WRITE FILENAME, MEMORY CARD NUMBER, AND TIME/DATE IN FIELD BOOK (for use in renaming files).

29. Stop recording by pressing "Stop" twice.

30. At the end of the recording session, verify that files are present.

a. Go back to "Waypoints, routes, files" from steps 13 and 14 .

b. Go to "Files."

i. Select the memory card number used to store files.

1) Verify file presence.

2) View file if desired (Note: Sensitivity parameter on far left of bottom row of buttons may need adjusting before data will appear).

31. Press Exit twice.

32. Shutting down: Press "Light/Power."

33. Select Power Off and Press Enter. 


\section{Designing and Conducting a Survey}

A successful operational SAV survey requires some preliminary planning. The user should select a series of parallel transects, at some fixed spacing, to be surveyed. When there is considerable depth variation in the survey area, it appears best to orient transects roughly perpendicular to the local depth contours (or shoreline). This orientation very precisely determines the depth at which SAV first occurs and makes for more accurate maps when spatial interpolation (gridding) is involved. Points needed to define these transects should be determined and entered into the HDS as GPS waypoints (see the section titled "Setting Waypoints," which follows). Each transect can be specified by two points (beginning and ending points), or three collinear points (line up point, begin recording point, and end recording point). The CHART capability of the HDS can be used to select these points and to navigate transects. During the survey the operator should manually record filenames, transducer depth, and times and dates associated with each logged file. This will be needed in post-processing to correct for tides and generate files ready for GIS mapping. An example datasheet for logging such information is provided in Appendix C. If operating in a tidally influenced area, a measured time history of tides relative to the local vertical reference (usually Mean Lower Low Water - MLLW) will also be needed. Tidal measurements will need to be collected before, during (at least once an hour), and after the survey for each site. Vertical tidal references should be identified during the survey site selection stage.

The authors also suggest that transects should not be too long. Using the required settings, data accumulates at a rate of $8 \mathrm{Mb} /$ minute; thus, a 5 -minute transect will result in a 40-Mb .SL2 file. Shorter files have several advantages. First, long recording sessions are more susceptible to data loss, such as from a power flicker. Second, it will probably be necessary to process a file multiple times before the optimum configuration parameters are determined. Shorter files will save time here. Lastly, the algorithm dynamically computes thresholds needed for processing based on the acoustic conditions of the individual file. If the file is so long that conditions such as bottom composition appreciably change over the length of the transect, the resulting parameter settings may not be ideal for either condition. The authors recommend that transects be limited to no more than 5 minutes recording time. This corresponds to a roughly $600-\mathrm{m}$ length at a well-suited boat speed of 4 knots. If more time is required to complete a 
longer transect, one file can be closed and the next opened up quickly. Guidance is offered for two types of survey designs - repeated parallel lines in the same direction and repeated parallel lines in opposing directions.

Uni-directional parallel transects (Figure 12) are best suited for areas where one end of the transect terminates in the shallows. A site that is bounded by a navigable channel or deeper slough to one side, and a shoreline or shoal to the other, is an example of a situation in which unidirectional parallel transects should be employed. This prevents maneuvering the survey boat in the shallows, to line up for the next transect, and possibly damage shallow-water SAV beds.

Figure 12. Uni-directional parallel transects.

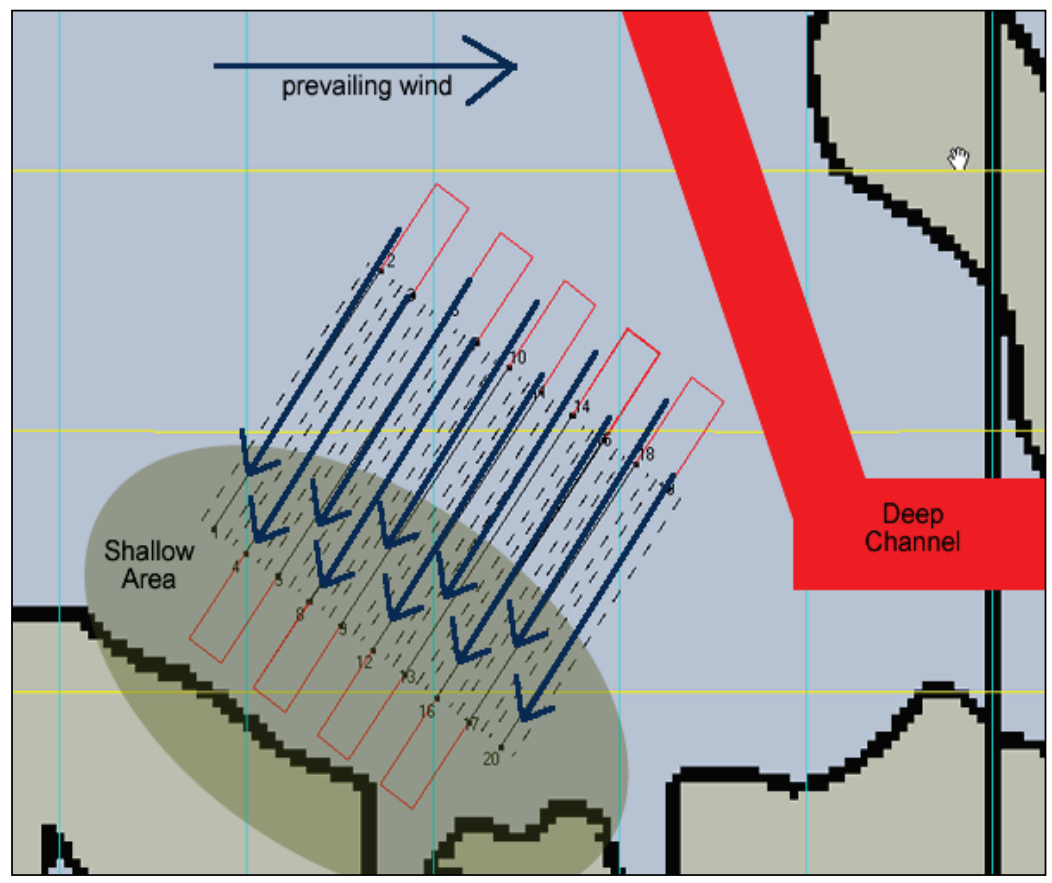

Approaches that use bi-directional parallel transects (Figure 13) work well in areas where spatial restrictions are less significant (i.e. an area within a larger SAV bed that has little depth change and is not restricted by shoreline, shoals, or other obstacles). When designing a bi-directional survey, consider the vessel's turning capabilities and the expected local conditions (tidal flow), two factors that will help determine how far past the final collection point the vessel operator should travel before setting up for the next transect. The more time spent approaching the start-recording waypoint, the straighter the transect will be. Straight transects on a preplanned path are particularly important for repeated surveys in the same location. 
Figure 13. Bi-directional parallel transects are surveyed in opposing directions.

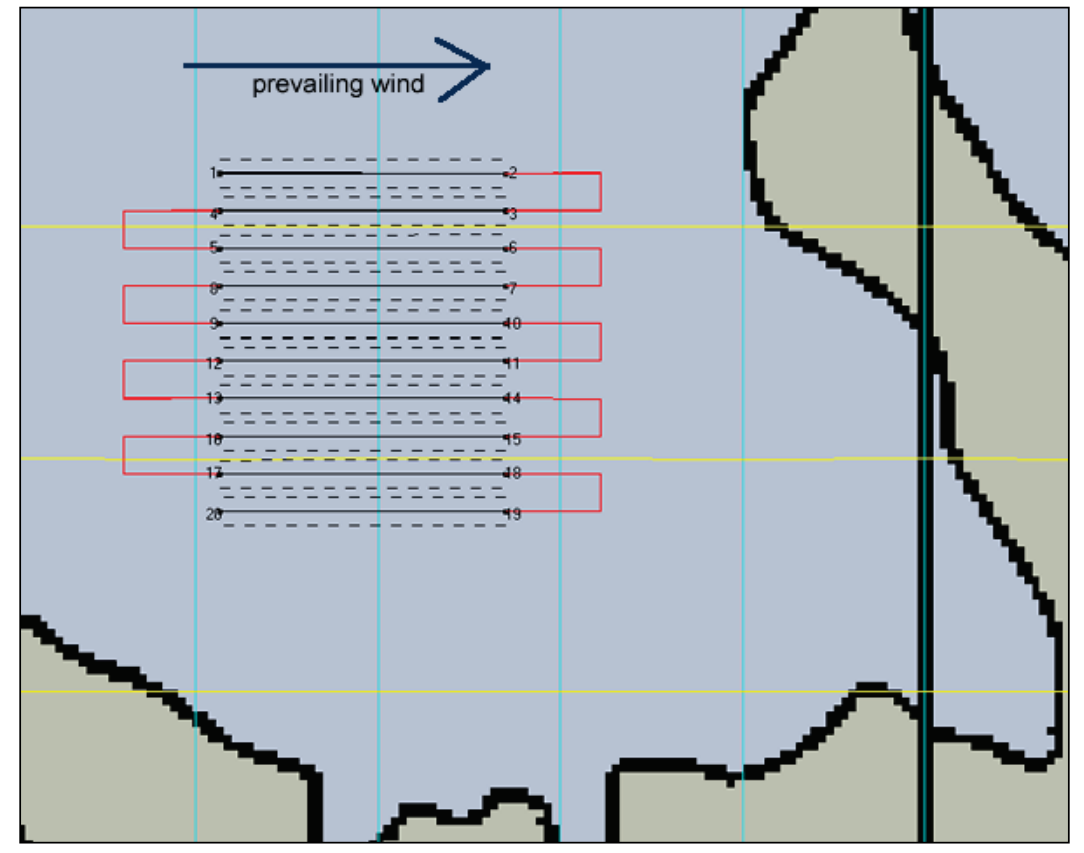

Regardless of method, keep the following guidance in mind:

1. End the survey line at a point that allows sufficient turning around of the vessel (i.e. not right up to a shoreline or restrictively shallow water).

2. Where a shoreline is the inside boundary of a set of lines, carefully idle back to the offshore end of the transect (i.e. conduct each line in the same direction).

3. An allowance of approximately $50 \mathrm{~m}$ is suggested prior to beginning a survey of the transect line to be sure the vessel operator has a correct heading, given the local conditions.

4. In the case below, consider the prevailing wind direction when establishing the track (see environmental conditions below).

5. Avoid crossing the path of the boat while recording, since the propeller entrains small bubbles in the wake that are highly reflective acoustically and can mask the intended signal (plants and bottom).

\section{Environmental conditions}

Conditions play a large role in an operator's ability to keep the vessel on track. In coastal areas, tides and wind need to be taken into account prior to conducting the survey. 


\section{Tidal effects}

1. When unfamiliar with an area, deploy an anchor attached to a floating crab-trap-type buoy to visually observe the direction of the tidal flow.

2. If the flow is perpendicular to the transect lines, account for this in the vessel heading and angle the vessel along the line with the bow turned into the tide. Following the GPS navigation guidance on the HDS CHARTS window will show the true track of the boat and allow the operator to make needed corrections.

3. If possible, run the transect line either into (preferred) or with the tide.

4. Adjust vessel power to maintain a nearly constant speed over ground (SOG) - a range of 2-6 knots is suggested.

a. Decrease engine RPM when running with the tide.

b. Increase engine RPM when running against the tide.

5. Strong tidal flow causes SAV canopies to lay down in the direction of flow, greatly reducing the in situ canopy height. If accurate measures of in situ canopy height are important, then it would be highly desirable to schedule the survey during high slack tide. Vegetation percent coverage is not too sensitive to plants lying over due to tidal currents.

\section{Wind effects}

Depending on the survey vessel's susceptibility to wind (cabin versus noncabin vessels), wind may affect the path along the given transect line.

1. If possible, run the transect line either into (preferred) or with these forces.

2. Adjust vessel power to maintain a nearly constant speed over ground (SOG).

a. Decrease engine RPM when with the wind.

b. Increase engine RPM when against the wind.

3. For those not familiar with the handling characteristics of the vessel, several practice transects are recommended.

a. Note speed and direction of deviations from transect lines and record this information in the field notebook.

b. Correct for deviations while conducting the survey by adjusting speed. 
In addition to navigational challenges, wind affects acoustic conditions within the upper water column. Wind, and resulting waves, entrain small bubbles in the upper water column. These highly reflective bubbles may mask the "quiet zone" necessary for detecting submersed vegetation. This is not a problem in deep waters, except for the boat heave effects on the detected bottom depth. In shallow waters, the loss of the quiet zone may make plant detection impossible. Strong ( $>10$ knots), steady winds may make it necessary to reschedule sampling activities.

\section{Setting waypoints}

Transect waypoints are specified by latitude/longitude pairs. Two waypoints are minimally needed to define each transect. It may be desirable to specify each transect using three waypoints - the first being a line-up point, followed by the start-recording and the stop-recording points. Transect points may be selected in two ways - using digital (or paper) maps (including the HDS CHART), and field selection during a preliminary site visit. If time is available, the second method is of course preferred because it allows users to see conditions that may not be evident from a map. All waypoints should be entered and saved into the HDS as GPS waypoints.

Map selection of waypoints: Prior to field work, obtain a chart or use the HDS chart to select field sites, and then follow the process outlined below.

1. If using the HDS chart, open the Chart page.

2. Place the cursor on the Chart page at the desired location to set the waypoint, and select New Waypoint.

3. When the New Waypoint menu appears, select Save.

If using latitude and longitude values selected from an external chart, go to the Utilities page.

1. Go to the Waypoints screen.

2. To open the Waypoints screen menu, press the MENU key from the Waypoints screen.

3. Select New.

4. From this screen, type in latitude and longitude as well as the waypoint name. Hit enter.

5. Double-check the position of the Waypoint on the Chart screen. 
Field selection of waypoints:

1. Position the survey vessel $50 \mathrm{~m}$ away from selected waypoint position. Motor towards the beginning of the survey transect.

2. Press the MENU key (soft key). From the Chart menu, select New Waypoint.

3. When located over the beginning of the transect, begin the process to save the Waypoint. When the New Waypoint at Vessel menu appears, select Save.

4. Record the site name, transect number, waypoint number, and GPS position in a field notebook.

5. Repeat these steps for all waypoints.

To delete waypoints:

1. From the Pages screen, select waypoints, routes, and trails, and press ENTER.

2. When the waypoints screen appears, select a waypoint to navigate to from the waypoints list, and press MENU.

3. The waypoints screen will appear. Press the Edit soft key.

4. From the Edit Waypoint menu, select Delete.

\section{Navigating transects}

Key concepts to remember when conducting a survey are outlined below.

1. Do not run the survey as one file. Save the data for individual (preferably straight) survey lines by saving and renaming each line of the surveys individually.

2. While running the transect, avoid over-compensating course corrections, which may occur due to the short lag time between GPS updates and the visual tools on the HDS screen.

a. Make subtle changes when off track.

b. Allow updates of the screen to occur before making additional adjustments (the external GPS helps here because it updates position five times as quickly as the internal GPS in the HDS unit).

c. To avoid over-compensating, select a distant object to steer toward when on track, only occasionally checking position on the HDS. 
3. Verify that the screen is "zoomed in" at the appropriate range--this may be all the way in to follow the line. Some operators prefer the ability to see the end point on the screen at all times.

4. Maintain a constant speed when on recording transects. This should be within the range of 2-6 knots.

\section{Conducting a survey}

The following steps should be followed in conducting a survey.

1. Display Sonar and chart pages as a combo page.

a. Prior to selecting the active page, adjust the zoom on the chart page to the appropriate scale. Once the Sonar page has been selected as the active page, it will be impossible to adjust the zoom on the chart without switching the active page.

b. Use the keypad to select the Sonar page as the first page for the combo display. This is the primary page that can be edited during processing (left side of the screen).

c. Select the chart pages from the primary pages combo display list. This is the secondary page (right side of the screen). Press ENTER.

d. Pressing the MENU key will open the active panel's context menu.

e. If switching the active page becomes necessary, press and hold the PAGES key down for 1 second.

2. Approximately $50 \mathrm{~m}$ prior to beginning the survey, examine the transect line to be sure the vessel has a correct heading given the local conditions.

3. $20 \mathrm{~m}$ before the first waypoint, access the Sounder Logging Menus to begin recording:

a. Press "Menu."

b. Go to "Log Sonar," and press Enter.

c. Set up the recording session (HDS will reset options if steps are not followed in order).

i. Choose save location (Memory card 1 or 2, NOT Internal).

ii. Set "Bytes per sounding" to 3200.

iii. Select "Log all channels." This will record the 200-kHz skimmer, and all three channels of the StructureScan transducer (left, right, and down), using the frequency selected in step 22b). An .sl2 file will be generated. It is acceptable to use the default file names offered by the HDS system - SONARxxxx. These file 
names will need to be renamed, using a date/time format as described later, before processing is completed.

iv. Press Record to begin the recording session.

v. WRITE FILENAME, MEMORY CARD NUMBER, AND TIME/DATE IN FIELD BOOK (for use in renaming files).

4. Stop recording by pressing "Stop" twice.

5. At the end of the recording session, verify that files are present.

a. Verify the file has been recorded by performing step 30 (section titled "Recording").

b. Go to "Files."

i. Select the memory card number used to store files.

1) Verify file presence.

2) View file if desired (NOTE: Sensitivity parameter on far left of bottom row of buttons may need adjusting before data will appear).

6. Press Exit twice.

7. Repeat at the beginning of each transect.

8. Shutting down: Press "Light/Power."

9. Select Power Off and Press Enter.

Various types of data should be manually recorded during a survey for later use. Appendix $\mathrm{C}$ contains an example field data sheet that can be copied and used.

\section{Data file naming convention}

Default filenames generated by the HDS have the format SONAR $x x x x$ (where $x x x x$ are sequential numbers added by the HDS operating system). This is adequate for field data collection, given that typing in different names on the HSD during data collection can be slow and awkward. However, these files should be renamed after data collection and prior to processing to avoid possibly losing data due to duplicated filenames. All post-processing steps will require filenames in a date/time format:

Example: 
20110612_133200.SL2

corresponds to June 12, 2011 at 1:32:00 PM (13:32:00

is 24-hr time format)

Time and date are not available within the .SL2 files, so the filename is the only means of recording date and time for tidal correction and archival purposes. 


\section{Software Installation and Setup}

SAVEWS Jr. Version 1.0 is written in MATLAB and requires the system to have MATLAB R2011b installed or the MATLAB Compiler Runtime (MCR) Version 7.16. SAVEWS Jr. supports only 32-bit and 64-bit Microsoft Windows platforms. The procedures for software installation and setup are outlined below.

1. If MATLAB or the MCR is already installed on the system being used, skip to step 3.

2. SAVEWS Jr. requires the MCR to be installed on computers that are not running MATLAB. Run the MCRInstaller.exe file located on the SAVEWS Jr. distribution disk (this will require Administrator permissions). Follow the installation instructions on the screen.

3. Copy the SAVEWS Jr. Program to the folder (directory) of choice. The 32-bit distribution uses the filename SAVEWS_Jr_32.exe and the 64-bit distribution uses the filename SAVEWS_Jr.exe. Note: The phrase "the folder (directory) of choice" means that the executable can be placed anywhere on the computer. But users will need to know where they put it so they can run the program by double-clicking the icon or program name. Most users will choose to put the executable on their desktop and run it from there. Others may separate their work into project directories. If this option is selected, place the executable in a project directory with data files. Either method is acceptable; it is simply a matter of personal preference.

4. If the Finalize Jr. Program is not used, skip to step 8.

5. If the Microsoft .NET Framework 2.0 Service Pack 2 is installed on the system being used, skip to step 7 .

6. Install Microsoft .NET Framework 2.0 Service Pack 2. This can be found at the Microsoft Download Center. (http://www.microsoft.com/enus/download/details.aspx?id=1639)

7. Run the Finalize.msi installer (this will require Administrator permissions). The installer will walk users through the steps of installing Finalize Jr. on a system.

8. Verify installation and operation of SAVEWS Jr. Copy the test files (20120626_134202.SL2 and DEFAULT.sjrcfg) from the SAVEWS Jr. distribution and place them in a working folder (directory) of choice. 
9. Run the SAVEWS Jr. Program (double-click on the icon or program name) and select the 20120626_134202.SL2 file as the data input and DEFAULT.sjrcfg as the configuration file.

10. Press the "Process File" button. The program will take several minutes to run and it will generate a 20120626_134202.jpg file when finished. The 20120626_134202.jpg file will be in the same folder (directory) as the 20120626_134202.SL2 file. Graphically compare the 20120626_134202.jpg file with the VERIFY.jpg file that is in the SAVEWS Jr. distribution. If they appear the same, the program is operating correctly.

Users experiencing difficulty installing this software should contact Eddie Melton at ERDC (601-634-3498). 


\section{Version Notes (Version 1.0)}

Version 1.0 is the initial release of the SAVEWS Jr. code. This version uses dual-frequency (200-kHz, and 80o-kHz down-looking channel of StructureScan) processing. Training data for this version were obtained from a limited amount of sampling of estuarine eelgrass (Zostera marina) in New Jersey and Massachusetts, various freshwater macrophytes (pondweed, milfoil, and others) in Michigan and Wisconsin, and hydrilla in central Florida. This initial version has not been optimized for execution speed and is not capable of running in batch mode, i.e. the user must enter and process one file at a time. As additional environments are sampled and different conditions are encountered, it is anticipated that further modification to the code will be needed, resulting in subsequent versions. Feedback from users is welcomed in identifying shortcomings and getting suggestions on how the code may be improved.

\section{Processing}

The general sequence of steps the user follows in processing data is as follows:

1. Run a single (preferably small, $<20 \mathrm{Mb}$ ) file with an unturned configuration file (CF).

2. Generate a colorized echogram of the file along with the processed output graphic and ASCII file.

3. Recognize that initial processing will probably not generate satisfactory results, but will help guide the user in modifying the $\mathrm{CF}$ to achieve best results.

4. Iteratively change the $\mathrm{CF}$, preferably one variable at a time, until results appear to agree with the colorized echogram.

5. Use the resulting modified $\mathrm{CF}$ to process all transects taken in this sampling site.

6. Review each transect to verify that no further modifications to the $\mathrm{CF}$ are needed.

7. When all transects have been processed and accepted, run them through a post-processing program (FINALIZE) that concatenates all files, corrects for tides (if necessary) and transducer depth, and converts geographic coordinates (latitude and longitude) to a user-selected Cartesian coordinate system (UTM, state plane, etc). 
8. Enter the output of FINALIZE into a mapping or statistical analysis package.

In the section that follows, two files are processed to illustrate each of the steps described above.

\section{SAVEWS Jr. processor}

The first example file (Figure 14, file 20120626_134202.SL2, using the required file nomenclature described above) is from Cuttyhunk Harbor, Massachusetts. This file was sampled from high-energy, sand bottom locations near the harbor entrance. The graphic is generated by the processor and represents the 8-bit echo return intensity generated from the downlooking channel of the 80o-kHz StructureScan transducer. Hot colors (red and orange) represent high reflectivity (high values) and cool colors (blue and green) represent low reflective "quiet" conditions (low values). The roughly 4-minute recording traversed $440 \mathrm{~m}$, generated $34.6 \mathrm{Mb}$ of data, and almost 6000 pings. The recording began in the shallows $(\sim 1-\mathrm{m}$ depth) and ended in the deep $(\sim 5-\mathrm{m})$ area. Along the top edge of the figure is high return generated by transducer residual ringing and surface "noise" (micro bubbles near the surface). Below that, the water column becomes progressively quieter (cool colors) with increasing depth. The sand bottom is revealed as a narrow red/orange line beginning at around $1 \mathrm{~m}$, rapidly getting deeper at around ping 3000, and ending near the 5 -m depth. SAV is evident beginning near ping 1300 and extending to around ping 3000 at a depth of approximately $3.5 \mathrm{~m}$ (note that depth here is specified as the distance between the transducer face and the bottom, and that the transducer face is submersed at least $0.25 \mathrm{~m}$ in the water). In this region, plants (known to be dense eelgrass (Zostera marina)) are highly reflective, and the open water above these plants is not very "quiet" before it reaches the near surface noise. Beyond ping 3000, the near bottom waters are very quiet and there are several occurrences of what appear to be low-reflectivity plants (between pings 4700 and 5300). It is unclear whether these are plants, and if so, what species they are. However, they are growing at a considerably deeper depth than the known eelgrass bed, and they exhibit relatively low reflectivity. Figure 14 is actually generated by the first processing of the file described below - this material is covered out of sequence for illustrative purposes. 
Figure 14. Colorized echogram of acoustic transect at Cuttyhunk Harbor, MA.

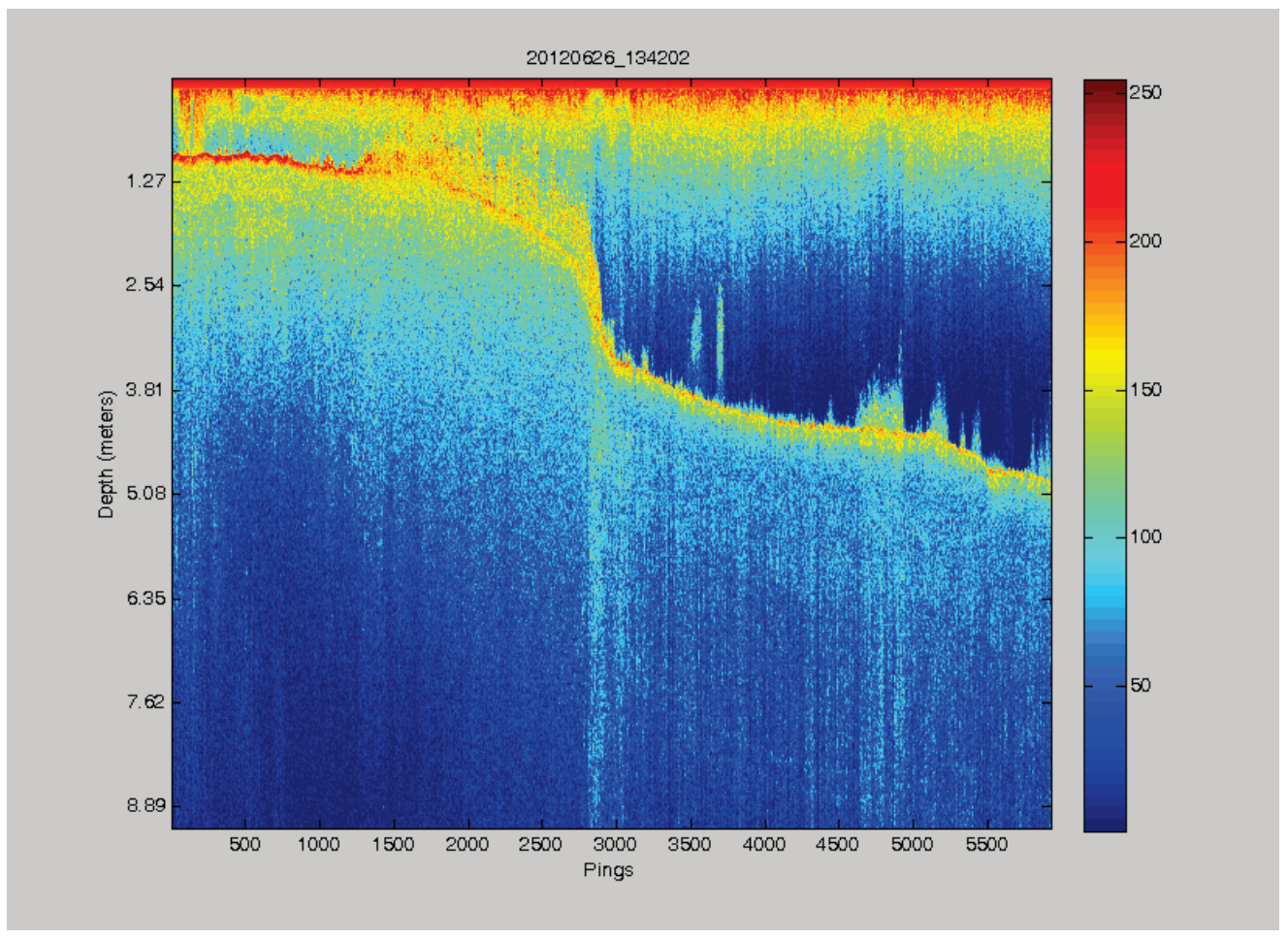

The process begins by initiating the program SAVEWS_Jr.exe, which produces the main graphic user interface (GUI) window (Figure 15). The user clicks browse and selects an .SL2 file from the subdirectory created to contain the survey data. Next the user clicks Browse to select a CF. A separate subdirectory containing just CFs (file type .sjrcfg) is recommended. A generic starter $\mathrm{CF}$ is picked for the initial run. These configuration settings are not expected to produce the best output, but obvious errors in the output will help determine which parameters need to be modified. To execute the program, the user then clicks Process file (Figure 16). A number of large libraries are read into memory at this point, which may take a minute or two.

When a particular file is run for the first time, the program parses the .SL2 file and reads it into memory while displaying the message Reading Data File [filename]. This is a relatively slow process and users are cautioned to be patient. Once this step is complete, the colorized echogram (Figure 14) appears overlain by a series of progress bars (Figure 17) indicating the stage and progress of processing. The sequence of progress bars is as follows: Computing Thresholds and Extracting Features, Finding Biggest Peaks, Finding Falling Edges, and Determining Canopy Tops. After reading the data files, the remaining actions occur relatively quickly; if a file is reprocessed, the reading step is skipped. 
Figure 15. SAVEWS_Jr data processing window, Generate output image is on by default.

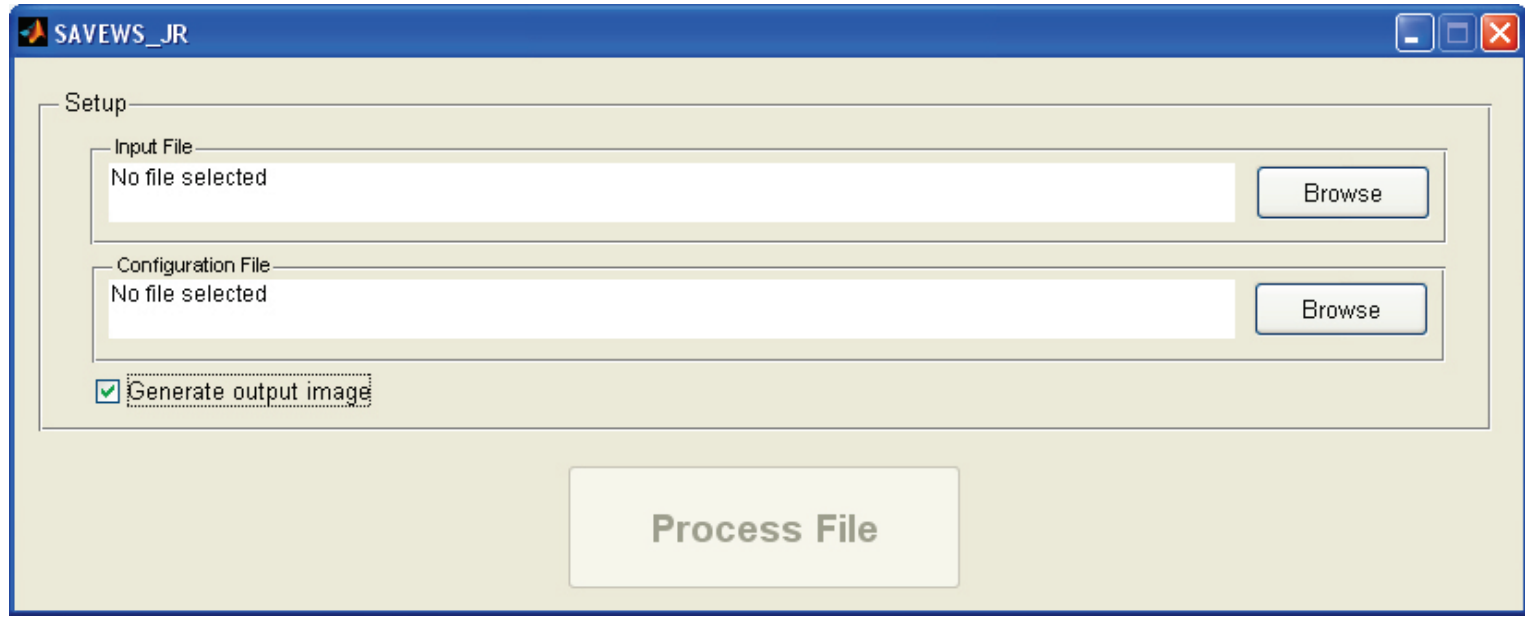

Figure 16. Processing GUI filled in and ready to start program.

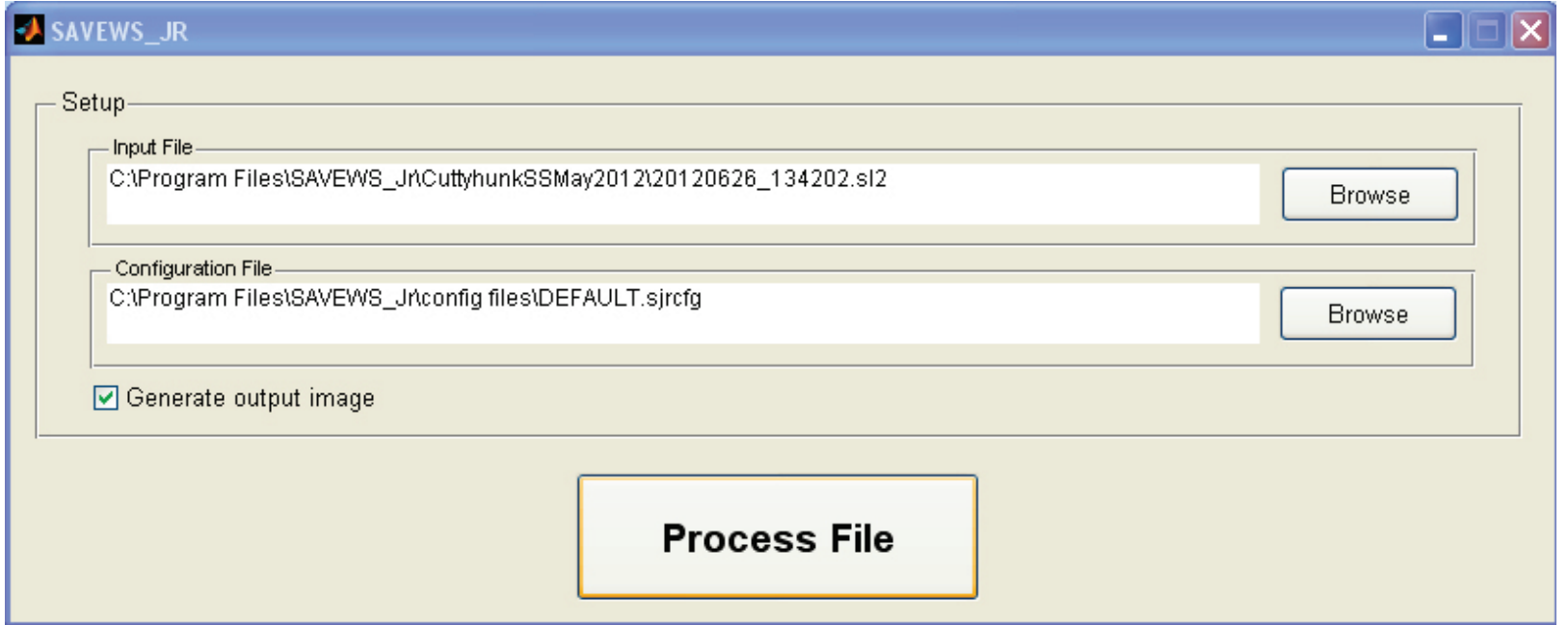

Figure 17. Display during processing.

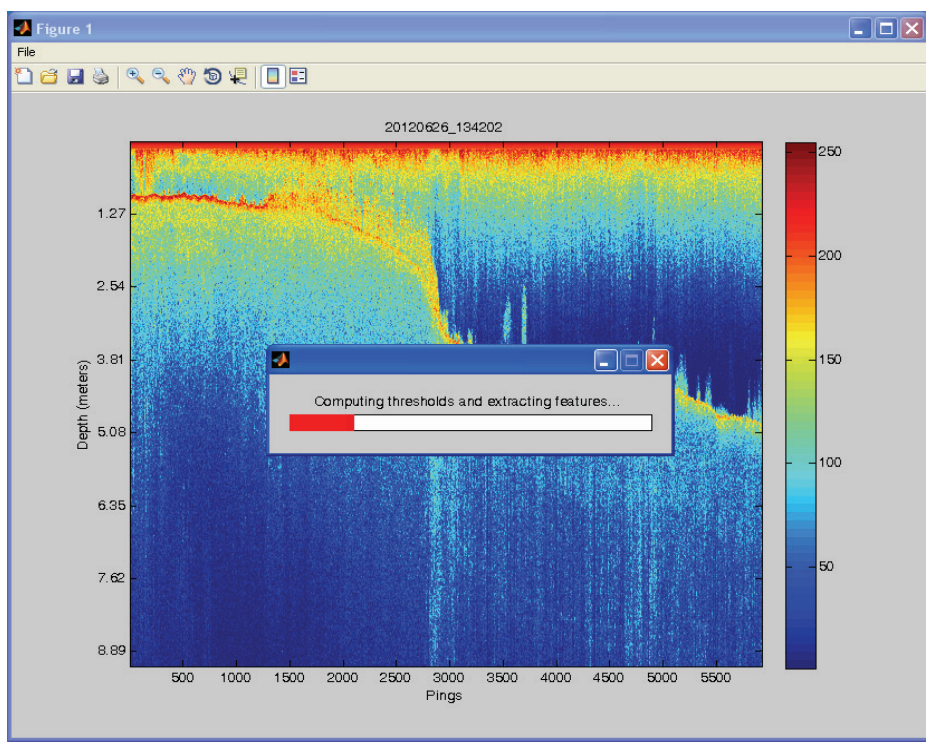


When processing is complete, three files are placed into the data subdirectory (location of .SL2 files):

1. filename._chart.bmp - colorized echogram of .SL2 file (e.g. Figure 14)

2. filename.jpg - graphic of processed output (Figure 18)

3. filename.sdf - comma-delimited ASCII file of processed output (Figure 19)

The graphic of processed output (Figure 18) contains three panels. The top panel overlays bottom and mean canopy height declarations onto the colorized echogram. The middle panel is a co-aligned data plot of SAV coverage, and the bottom panel is a similarly aligned data plot of mean canopy height. These plots are intended to make it easy for the user to readily evaluate the goodness of the output and to rapidly detect output

Figure 18. Graphic of processed output generated from a non-optimized CF (DEFAULT.sjrcfg).

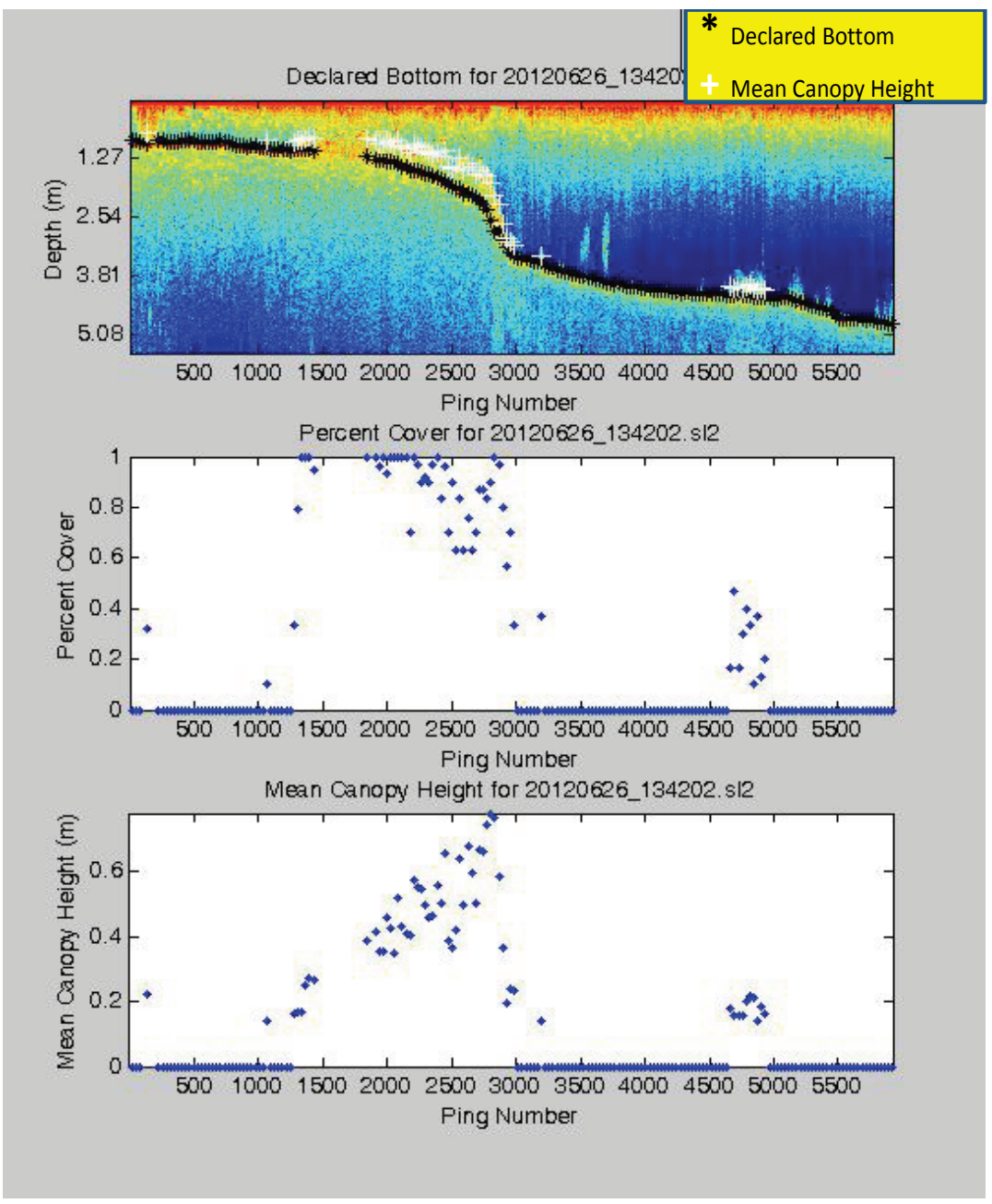


Figure 19. Raw output file (.SDF); a. processing parameters, and b. processed data.

\begin{tabular}{|r|l|r|r|}
\hline \hline 1 & \multicolumn{1}{|c|}{ A } & B \\
\hline 2 & Input Parameters & \\
\hline 3 & Date & $20120626 \_134202 . s / 2$ \\
\hline 4 & Time & $6 / 26 / 2012$ \\
\hline 5 & Pings Per Report Cycle & $13: 42: 02$ \\
\hline 6 & Mininum Gap for Ping Thresholds (m) & 30 \\
\hline 7 & Noise Threshold & 0.1 \\
\hline 8 & Minimum Vegetation Height (m) & 0.1 \\
\hline 9 & Minimum Vegetation Standard Deviation (m) & 0.03 \\
\hline 10 & Maximum Vegetation Depth Limit (m) & 5 \\
\hline 11 & Configuration File used: & DEFAULT.sjrcfg \\
\hline 12 & & \\
\hline
\end{tabular}

a. Processing information from top of .SDF file.

\begin{tabular}{|c|c|c|c|c|c|c|c|c|c|c|c|c|}
\hline 4 & A & B & c & D & $\mathrm{E}$ & $\mathrm{F}$ & G & $\mathrm{H}$ & 1 & $\mathrm{~J}$ & $\mathrm{~K}$ & L \\
\hline 1 & Rpt & Latitude & Longitude & Times(hr) & Day & Month & Year & Center Ping & Bottom $(\mathrm{m})$ & Canopy Height $(\mathrm{m})$ & Percent Cover & Depth to Canopy/Bottom (m) \\
\hline 2 & 1 & 41.424656 & -70.91875 & 13.7008 & 26 & 6 & 2012 & 15 & 0.883 & 0 & 0 & 0.883 \\
\hline 3 & 2 & 41.42466 & -70.91874 & 13.7011 & 26 & 6 & 2012 & 45 & 0.876 & 0 & 0 & 0.876 \\
\hline 4 & 3 & 41.424663 & -70.91872 & 13.7013 & 26 & 6 & 2012 & 75 & 0.908 & 0 & 0 & 0.908 \\
\hline 5 & 4 & 41.42467 & -70.91869 & 13.7019 & 26 & 6 & 2012 & 135 & 0.946 & 0.22 & 32 & 0.726 \\
\hline 6 & 5 & 41.424683 & -70.91864 & 13.7027 & 26 & 6 & 2012 & 225 & 0.876 & 0 & 0 & 0.876 \\
\hline 7 & 6 & 41.42469 & -70.91863 & 13.7029 & 26 & 6 & 2012 & 255 & 0.876 & 0 & 0 & 0.876 \\
\hline 8 & 7 & 41.424697 & -70.91862 & 13.7032 & 26 & 6 & 2012 & 285 & 0.895 & 0 & 0 & 0.895 \\
\hline 9 & 8 & 41.424704 & -70.9186 & 13.7034 & 26 & 6 & 2012 & 315 & 0.902 & 0 & 0 & 0.902 \\
\hline 10 & 9 & 41.424711 & -70.91858 & 13.7037 & 26 & 6 & 2012 & 345 & 0.902 & 0 & 0 & 0.902 \\
\hline 11 & 10 & 41.424717 & -70.91856 & 13.704 & 26 & 6 & 2012 & 375 & 0.908 & 0 & 0 & 0.908 \\
\hline 12 & 11 & 41.424724 & -70.91855 & 13.7042 & 26 & 6 & 2012 & 405 & 0.889 & 0 & 0 & 0.889 \\
\hline 13 & 12 & 41.424731 & -70.91854 & 13.7045 & 26 & 6 & 2012 & 435 & 0.876 & 0 & 0 & 0.876 \\
\hline 14 & 13 & 41.424734 & -70.91852 & 13.7048 & 26 & 6 & 2012 & 465 & 0.883 & 0 & 0 & 0.883 \\
\hline 15 & 14 & 41.424738 & -70.9185 & 13.705 & 26 & 6 & 2012 & 495 & 0.857 & 0 & 0 & 0.857 \\
\hline 16 & 15 & 41.424744 & -70.91848 & 13.7053 & 26 & 6 & 2012 & 525 & 0.895 & 0 & 0 & 0.895 \\
\hline 17 & 16 & 41.424748 & -70.91846 & 13.7056 & 26 & 6 & 2012 & 555 & 0.902 & 0 & 0 & 0.902 \\
\hline 18 & 17 & 41.424751 & -70.91844 & 13.7058 & 26 & 6 & 2012 & 585 & 0.895 & 0 & 0 & 0.895 \\
\hline 19 & 18 & 41.424754 & -70.91843 & 13.7061 & 26 & 6 & 2012 & 615 & 0.895 & 0 & 0 & 0.895 \\
\hline 20 & 19 & 41.424758 & -70.91841 & 13.7063 & 26 & 6 & 2012 & 645 & 0.914 & 0 & 0 & 0.914 \\
\hline 21 & 20 & 41.424761 & -70.91839 & 13.7066 & 26 & 6 & 2012 & 675 & 0.908 & 0 & 0 & 0.908 \\
\hline 22 & 21 & 41.424761 & -70.91838 & 13.7069 & 26 & 6 & 2012 & 705 & 0.889 & 0 & 0 & 0.889 \\
\hline 23 & 22 & 41.424765 & -70.91836 & 13.7071 & 26 & 6 & 2012 & 735 & 0.914 & 0 & 0 & 0.914 \\
\hline 24 & 23 & 41.424768 & -70.91834 & 13.7074 & 26 & 6 & 2012 & 765 & 0.908 & 0 & 0 & 0.908 \\
\hline 25 & 24 & 41.424768 & -70.91832 & 13.7077 & 26 & 6 & 2012 & 795 & 0.94 & 0 & 0 & 0.94 \\
\hline
\end{tabular}

b. Output data from bottom of .SDF file.

changes with subsequent runs using different configuration inputs. The final output (Figure 19) is a text version of the graphic output (Figure 18) that is used for post-processing or analyses. Variables used in the text output (Figure 19) are defined in Table 2. Before processing another file, the user must close the .SDF file (opened in Excel) or no output will be generated from subsequent runs. 
Table 2. Definition of output variables form raw output file (.SDF).

\begin{tabular}{|c|c|c|}
\hline Variable Name & Units & Definition \\
\hline Report cycle & Integer & Sequential number of output report summarizing $N$ pings \\
\hline Latitude & \multirow{2}{*}{$\begin{array}{l}\text { Decimal } \\
\text { degrees }\end{array}$} & \multirow{2}{*}{$\begin{array}{l}\text { Geographic coordinates in coordinate system set on GPS } \\
\text { (typically NAD83) }\end{array}$} \\
\hline Longitude & & \\
\hline Time & $\begin{array}{l}\text { Decimal } \\
\text { hours }\end{array}$ & $\begin{array}{l}\text { 24-hr time parsed from .SL2 filename and incremented with } \\
\text { HDS clock time (seconds elapsed since file start) }\end{array}$ \\
\hline Day & \multirow[t]{4}{*}{ Integer } & Day of month, parsed from .SL2 filename \\
\hline Month & & Month of year, parsed from .SL2 filename \\
\hline Year & & Year, parsed from .SL2 filename \\
\hline Center ping & & Ping number at center location of N-ping report cycle output \\
\hline Bottom & \multirow[t]{2}{*}{ Meters } & $\begin{array}{l}\text { Distance between transducer face and algorithm-detected } \\
\text { bottom }\end{array}$ \\
\hline Canopy height & & Mean height of detected plants in report cycle \\
\hline $\begin{array}{l}\text { Acoustic percent } \\
\text { cover }\end{array}$ & Integer & $\begin{array}{l}\text { Percentage of valid processed pings in which plants were } \\
\text { detected }(0 . .100) \text { (see Appendix D) }\end{array}$ \\
\hline $\begin{array}{l}\text { Depth to } \\
\text { canopy/bottom }\end{array}$ & Meters & $\begin{array}{l}\text { Distance between transducer face and first echo return } \\
\text { above USERNOISE (set in configuration file) }\end{array}$ \\
\hline
\end{tabular}

Examination of the processed output (Figure 18) reveals that bottom tracking appears reasonable and that much of the eelgrass bed (ping region 1400-3000) has been correctly declared, and some of the apparent sparse vegetation (ping region 4500-5500) has also been detected. An obvious problem is the lack of bottom or plant declarations in dense eelgrass at ping region 1500-1800.

To understand how output problems can be corrected, it is necessary to understand the configuration parameters defined within the CF. A full listing of the CF (DEFAULT.sjrcfg) used to create the first example is shown in Appendix B. Parameters are grouped into Basic, Intermediate, and Advanced categories. The Basic group contains parameters that are expected to change routinely. The Intermediate group consists of somewhat more advanced parameters; users should have some familiarity with these parameters before changing them. The Advanced group consists of parameters that require an in-depth knowledge of the algorithm to manipulate; these parameters generally should not be changed. Users are encouraged to read the description of each parameter in the example $\mathrm{CF}$ (Appendix B). 
When a file is run for the first time, it is useful to allow the algorithm to automatically pick the usernoise parameter value. This is done by setting usernoise $=0$ and percentile $=75$ (Appendix B). The result in the example was that the algorithm picked a usernoise value of 149 (line 7 , Figure 19a). The key to the missing output is that this region is very "noisy," i.e. there is not a clearly defined "quiet zone" between the top of the plants and the surface for the usernoise threshold selected. As the usernoise threshold increases, there will be less sensitivity to water column noise, and also less sensitivity to vegetation detection. By increasing the usernoise threshold, users may be able to recover data from the missing region. This can be done by increasing the percentile value, or by manually setting the usernoise threshold higher. The second approach was used in the example and the value for usernoise was changed from o to 160. Improvement in the reprocessed output is evident as shown in Figure 20. While the gap of missing output has been filled in, this action has occurred at the cost of some plant detection sensitivity. A very slight decrease in canopy height and percent coverage in the detected vegetation can be noted. There is an unavoidable tradeoff between noise rejection and detection sensitivity.

A second example was run (Figure 21) to illustrate some other configuration parameters. The selected transect is Eurasian watermilfoil in a northern Wisconsin lake. Several locations along the transect exhibit dense tall vegetation with a noisy water column above. Also, the bottom is not clearly evident at the beginning of the file and in ping region 2300-2500. Processing begins with the starter CF (DEFAULT.sjrcfg, Appendix B) used in the previous example, and Figure 22 is generated. Several problems are immediately evident. Output data are missing from the start of the file (ping region 0-250); apparent false detects are occurring near the end (ping region 2700-3000); and bottom tracking is erratic in ping region 500-750. The automated threshold picker selected usernoise $=95$.

Two types of problems occur in this scenario-vegetation detection and bottom tracking. The first modification necessary is to correct missing vegetation detections and false detections. The following parameter changes are made to improve vegetation detection performance:

1. Increase the usernoise value from 95 to 115 . This will reduce sensitivity to water column noise evident in ping region 0-250, and possibly eliminate false detects near the file's end caused by hypersensitivity of a low threshold. 
2. Decrease the startdepth value from 0.5 to $0.3 \mathrm{~m}$. The near surface noise is minimal, relative to the previous example. This decrease may help reduce data rejection in ping region $0-250$.

Figure 20. Reprocessing file 20120626_134202 with usernoise=160.

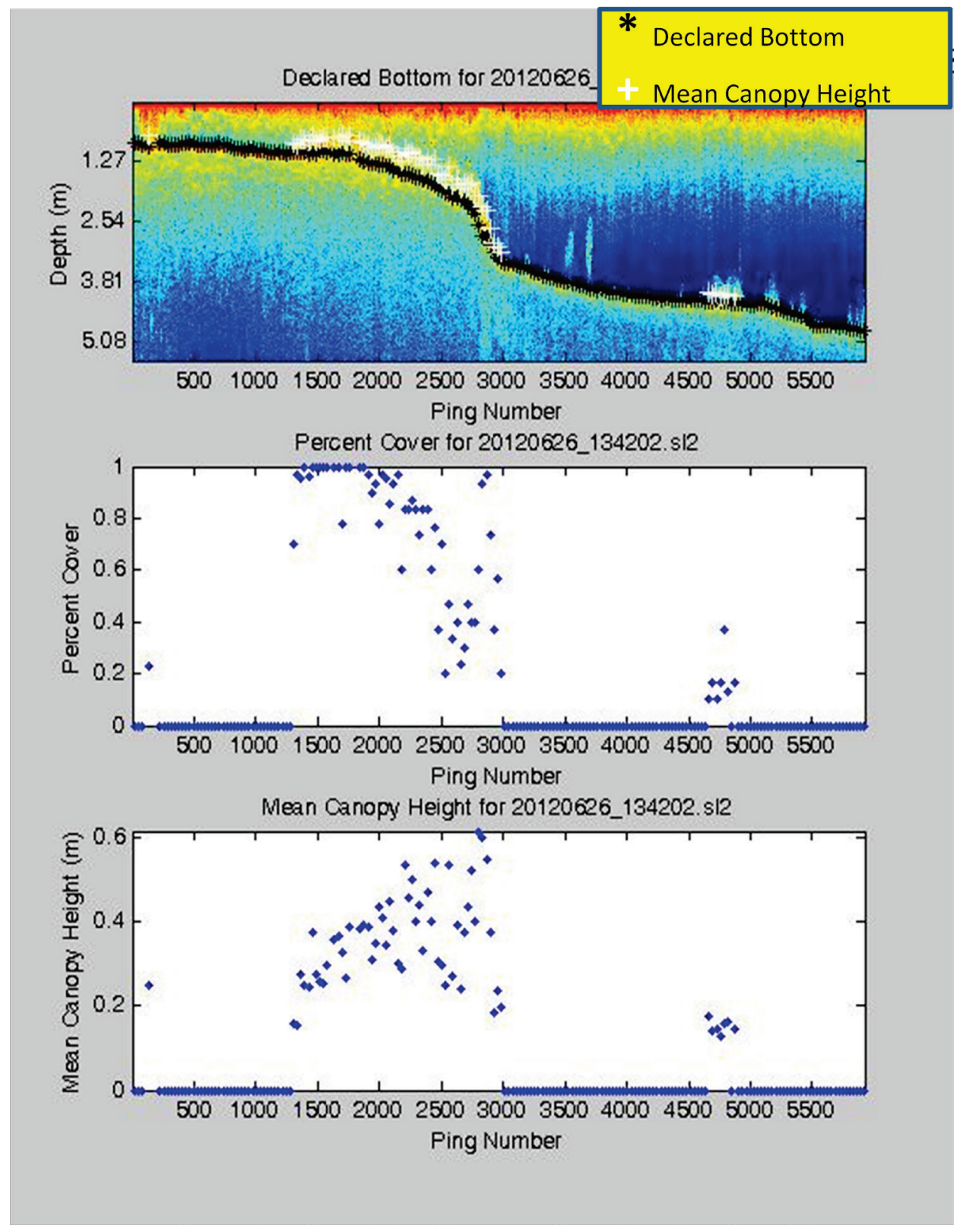


Figure 21. Colorized echogram of acoustic transect of Eurasian watermilfoil in northern Wisconsin.

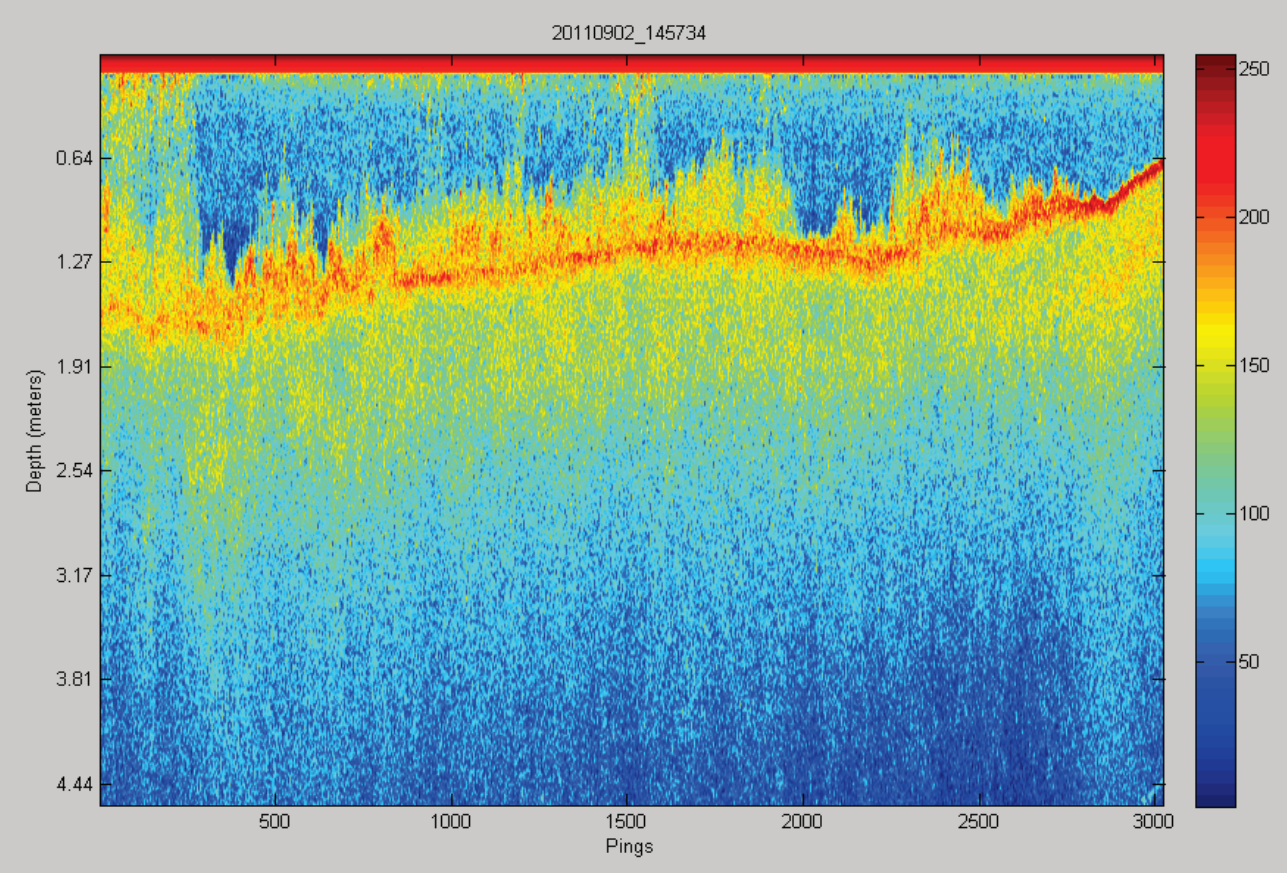

Output from these modifications is shown below (Figure 23). Reasonable vegetation detections are now being generated from ping region 0-250, and false detections near the end have been eliminated. Bottom tracking in ping region 500-800 is still erratic. A second parameter modification is made to improve bottom tracking:

Set the bot_change_tol value to $0.10 \mathrm{~m}$ (from $10 \mathrm{~m}$ ). This activates the median filtering of bottom depth declarations. In this case, when the difference between the current bottom depth and the nine-element (bot_med_filt_size) median value, centered at the current depth, exceeds $0.10 \mathrm{~m}$, the bottom depth will be reset to the median value. This is more of a cosmetic fix than a true signal processing fix, but it can be handy in some situations.

The reprocessing results (Figure 24) exhibit the desired depth smoothing in ping region 500-800. In this case, the cause of the original erratic bottom depth declarations is unknown - they may have a legitimate physical cause. However, the modification made in the example shows how median filtering can be used to smooth depths, if desired. Median filtering preserves sharp discontinuities in the string of depth estimates - unlike use of a moving average filter. In very dense vegetation, bottom depths frequently become erratic and use of median filtering would be warranted. 
Figure 22. Processed output generated from a non-optimized CF (DEFAULT.sjrcfg).

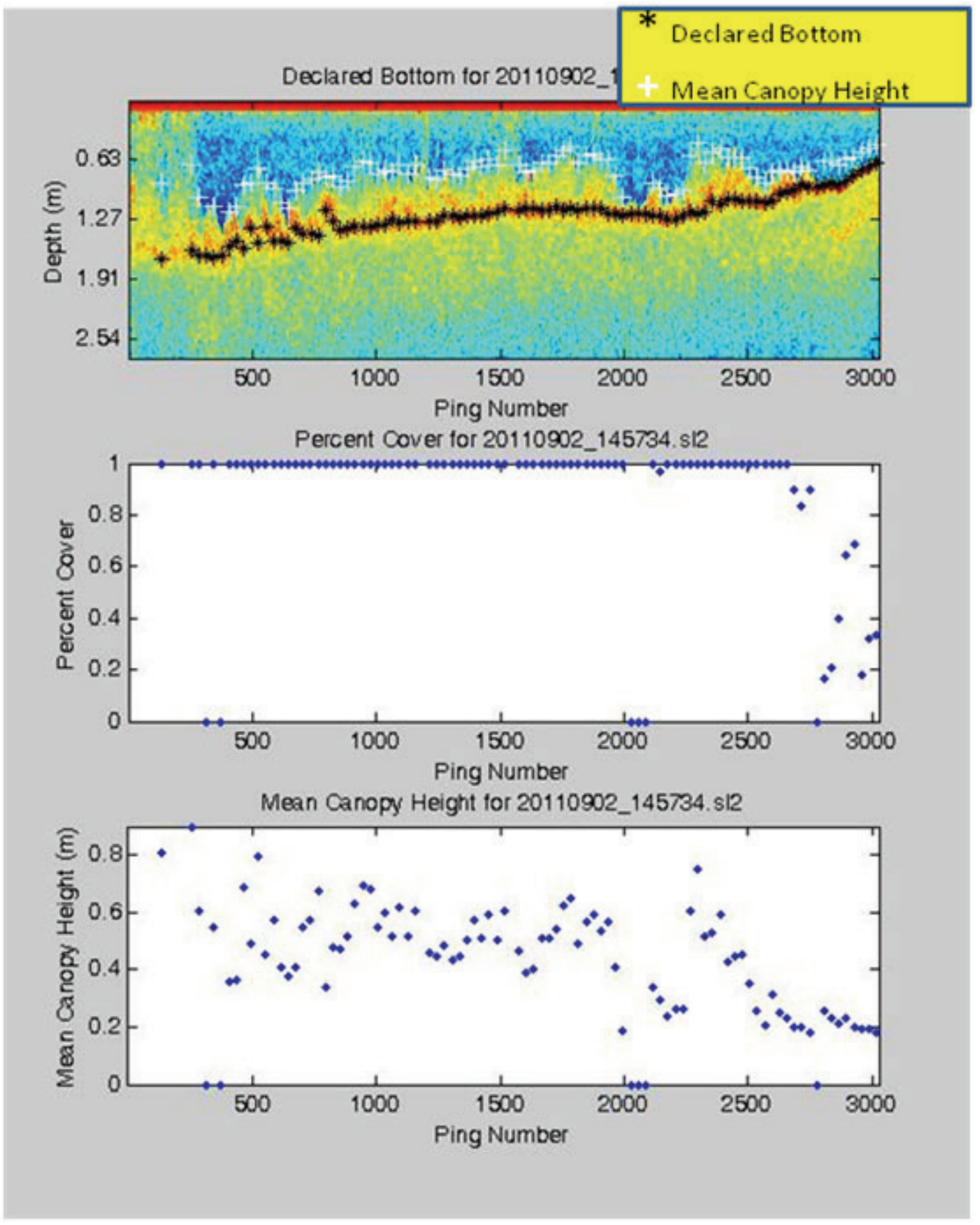


Figure 23. First reprocessing file 20110902_145734 (usernoise $=115$, startdepth $=0.3$ ) designed to improve vegetation detection performance.

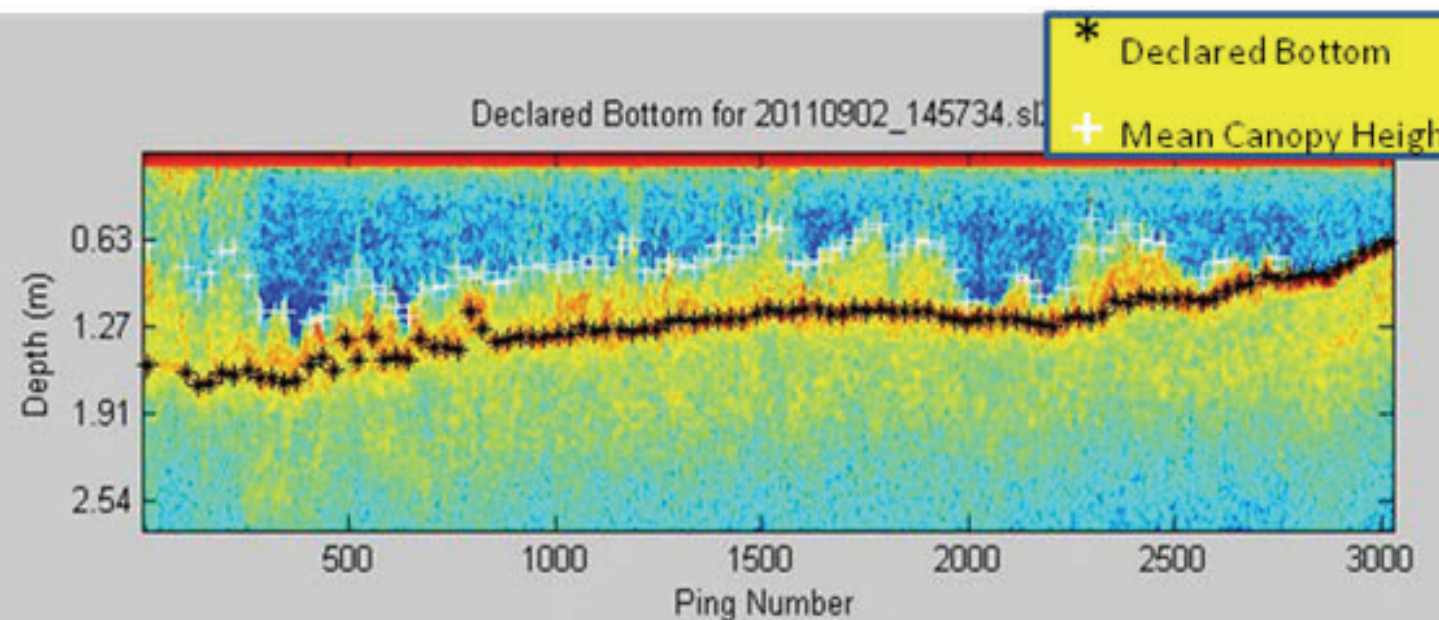

Percent Cover for 20110902_145734.s12
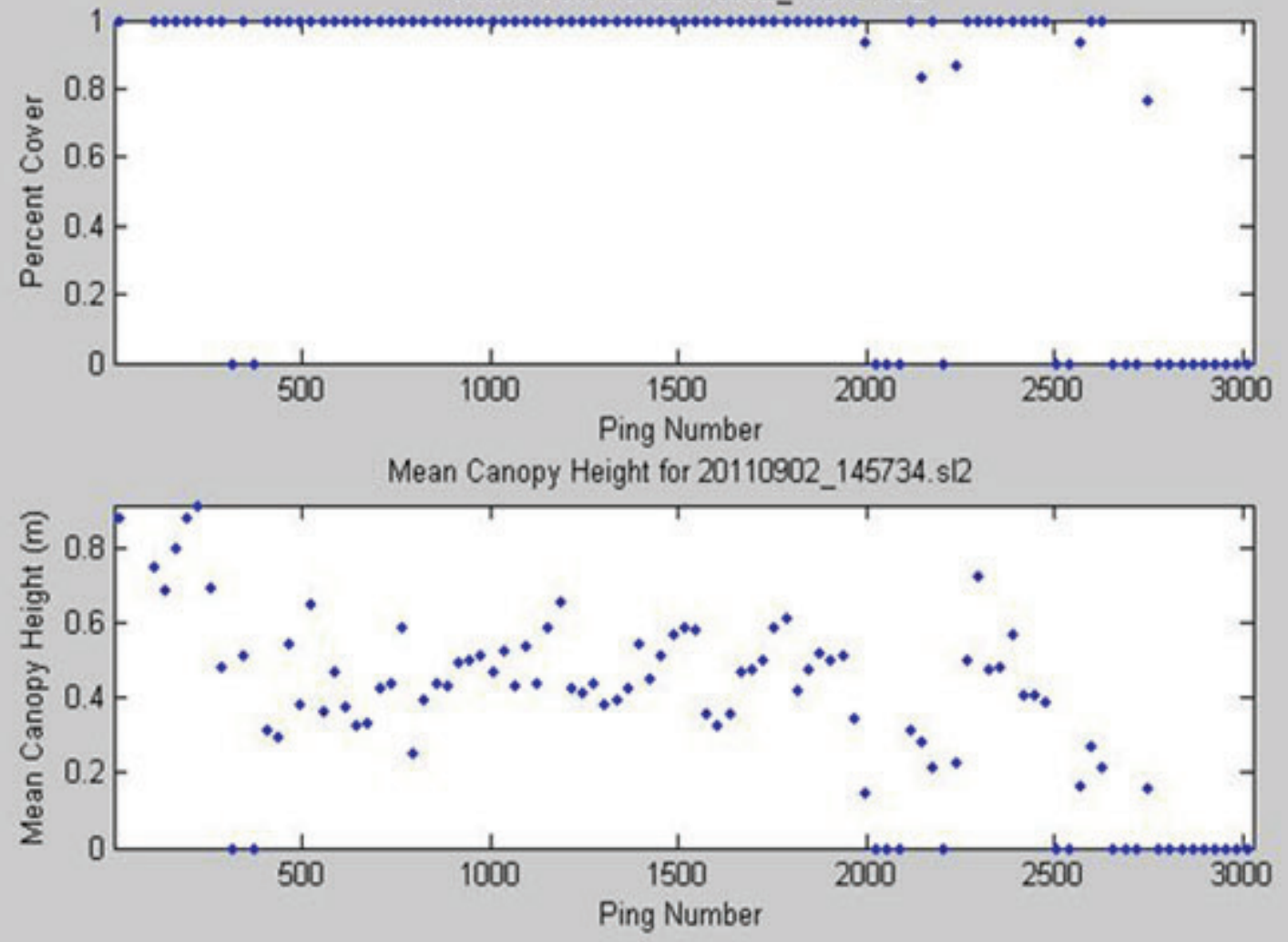
Figure 24. Second reprocessing file 20110902_145734 (bot_change_tol $=0.10 \mathrm{~m}$ ) designed to smooth erratic bottom depth declarations.
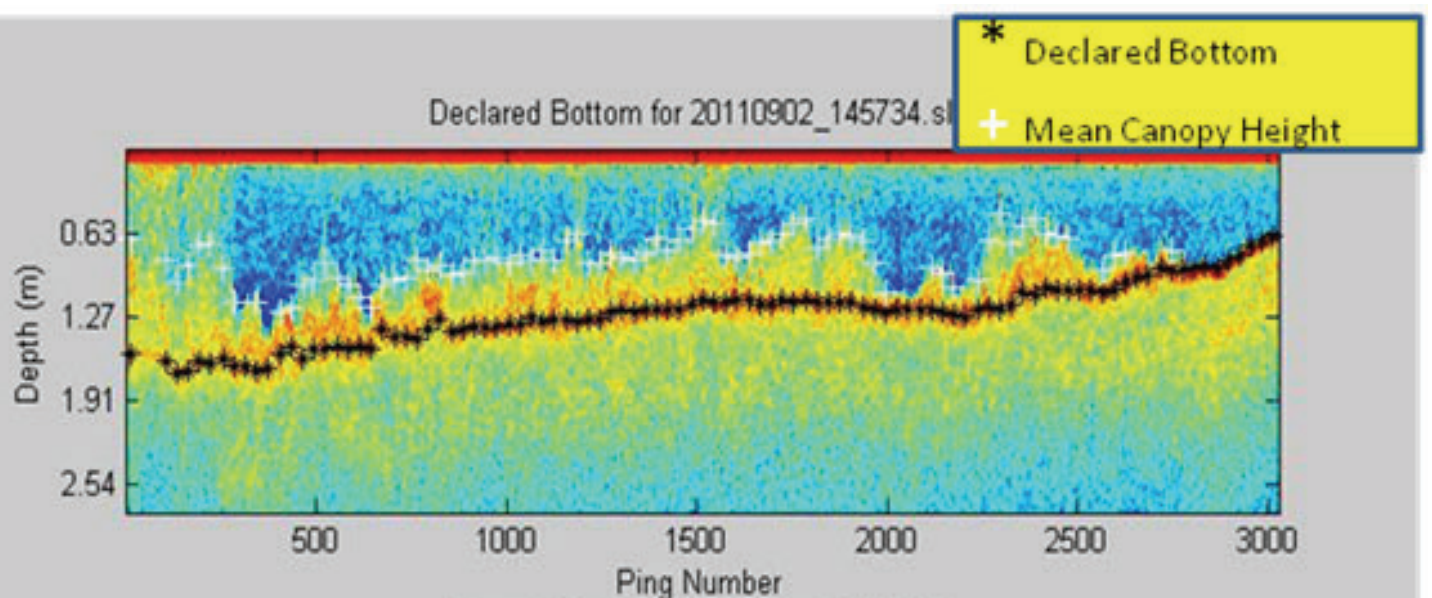

Percent Cover for 20110902_145734.s12

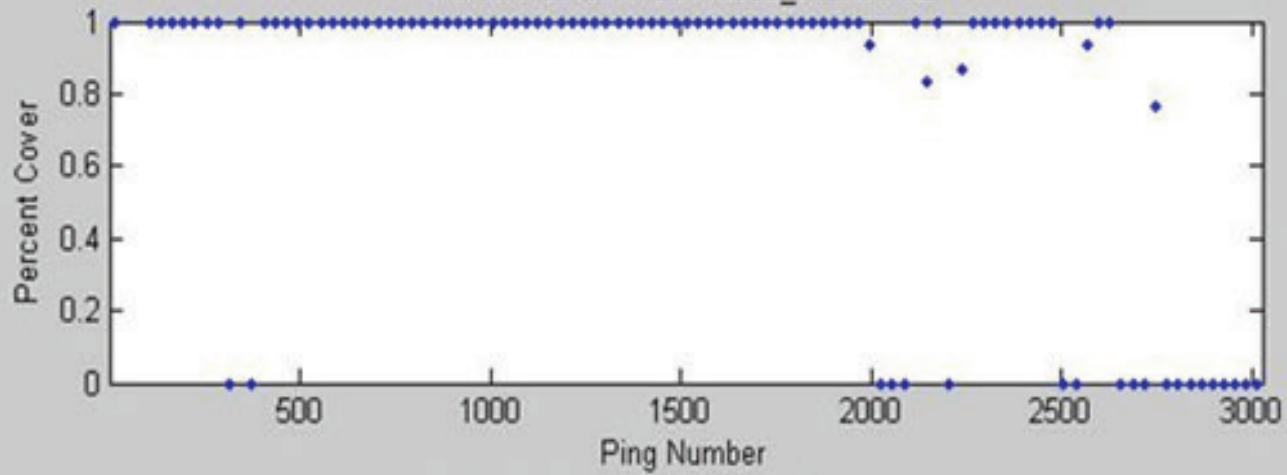

Mean Canopy Height for 20110902_145734.s12

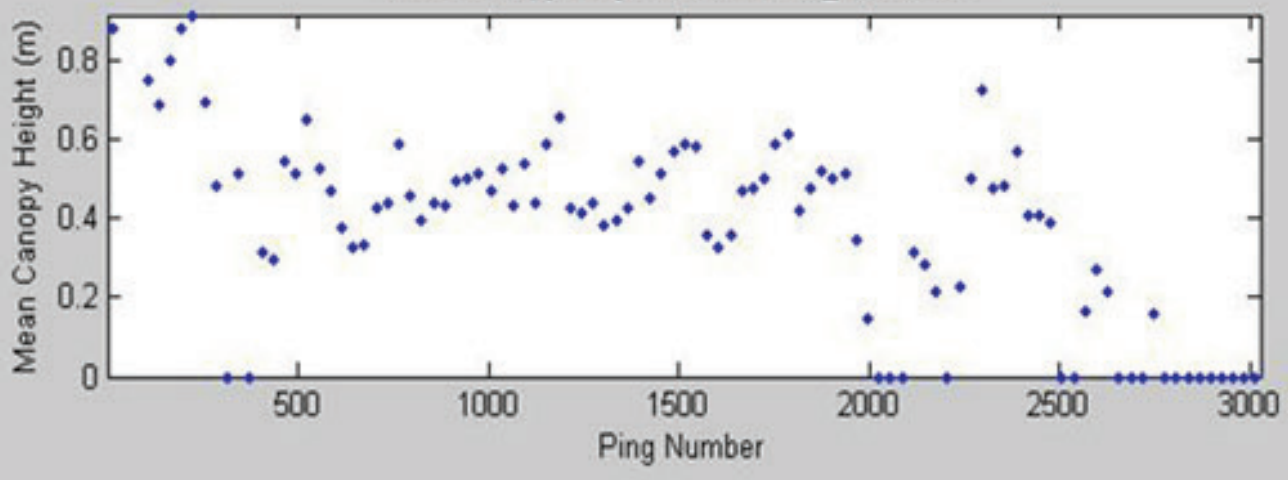

The two processing examples above illustrate how the CF can be adjusted to align output of a single file with the user's heuristic interpretation of the echo signal. An acoustic survey typically involves many transects collected from a localized region. Optimizing the $\mathrm{CF}$ for each transect in the survey would be unreasonably time-consuming and would lead to inconsistent detection sensitivity among transects. To achieve best performance, users 
are advised to select a "typical" and small $(<20-\mathrm{Mb})$ file from within the localized region to iteratively adjust the CF. This optimized CF can then be used to process all other files collected in this region. The user should examine and evaluate the output graphic as a quality control step. If bottom or plant type conditions change significantly over the spatial extent of the surveyed region, it may be necessary to adjust some parameters further.

The above examples began with a generic starting CF (DEFAULT.sjrcfg, Appendix B), which was not optimized for any particular set of environmental conditions. If an application is typically within some specific environment type (eg. Florida hydrilla, coastal eelgrass, etc), users are advised to develop a "customized" starting CF, optimized for specific conditions. This process will save time in arriving at the final $\mathrm{CF}$.

\section{Post processing}

The post-processing program FINALIZE makes depth corrections, coordinates projections to State Plane values, and optionally adds the distance along transects and cross track errors. The individual SDF files are concatenated into a single, comma-delimited ASCII text file ready for entry into a mapping or statistical analysis program. In addition to the SDF files that are to be included, the program requires a data file of tide measurements, a file of SDF filenames, and in some cases, a transect waypoint file. Steps in creating these files and running the FINALIZE program are described below.

1. Tide data file. Figure 25 is an example tide file. This ASCII space-delimited text file can be generated using any text-editing program, such as Microsoft Wordpad or Notepad. The first line is for documentation only. Each subsequent line contains the integer month, integer day of month, time (decimal hours local time, $24 \mathrm{hr}$ ), and tide (feet) relative to the selected reference plane. The first data line of the file must contain a tide measurement BEFORE the first recorded SDF file. The last data line must contain a tide measurement

Figure 25. Tide data file must contain integer month and day, decimal hours local time, and tide (ft).

\{tide data: mm,dd,hh.hh,tide (ft)

80111.559 .4

80111.759 .3

80111.909 .2

80112.069 .0

80112.248 .9

80112.568 .6

80112.748 .2

80112.907 .9

80113.067 .6

80113.247 .2

80113.407 .0

80113.566 .5

80113.736 .1

80113.905 .6 
AFTER the last recorded SDF file. If this condition is not met, the program will give a warning message and halt execution. If a tide measurement was not made at the correct time during data collection, it will be necessary to estimate one and enter it.

2. File listing SDF files. Figure 26 is an example file. Each line of the file corresponds to a single SDF file. It is not critical to have this list ordered in any particular way, but it may be convenient to order the files chronologically. The easiest way to generate this file without having to type all the 15 -character filenames is to enter the COMMAND PROMPT program (DOS emulator) and type: $\mathbf{d i r} / \mathbf{B} / \mathbf{O N}$

*.SDF > filelist.txt from within the proper directory. This will make a list of the 15-character filenames for the SDF files. Users should take care to eliminate any aborted files from the list.
Figure 26. The list file must contain SDF filenames, in date_time format, transect ID \#, depth of transducer face $(m)$, and replicate \#.

20120801_11400010.201

20120801_11440020.201

20120801_11490030.201

20120801_115600 40.201

20120801_13030060.201

20120801_13110070.201

20120801_13200080.201

20120801_13260090.201

3. Waypoint coordinate data file. Computing distance along a transect and cross-track error (error distance off intended path) is an optional feature of FINALIZE, which the user may or may not select. If selected, the user must input a file of waypoint coordinates. An example waypoint coordinate file is contained in Figure 27. This ASCII space-delimited text file can be generated using any text-editing program, such as Microsoft WordPad or Notepad. The first line is for documentation only. Each subsequent line contains the longitude, latitude, transect number, and a point identifier. Note that West

Figure 27. Waypoint file for computing location along transect.

\begin{tabular}{|lrrrl|}
\hline Lon & Lat & Transect & Pt ID & \\
70.35202 & 43.45018 & 1 & 1 \\
70.35355 & 43.45305 & 1 & 2 \\
70.35331 & 43.45288 & 2 & 1 \\
70.35279 & 43.45133 & 2 & 2 \\
70.35245 & 43.44973 & 3 & 1 \\
70.34715 & 43.4553 & 3 & 2 \\
70.3472 & 43.45551 & 4 & 1 \\
70.35296 & 43.44967 & 4 & 2 \\
70.35366 & 43.44922 & 6 & 1 \\
70.34739 & 43.45547 & 6 & 2 \\
70.34773 & 43.45546 & 7 & 1 \\
70.35286 & 43.4501 & 7 & 2 \\
70.35294 & 43.45037 & 8 & 1 \\
70.34794 & 43.45557 & 8 & 2 \\
70.34794 & 43.45576 & 9 & 1 \\
70.35326 & 43.45003 & 9 & 2 \\
& & & \\
\hline
\end{tabular}


longitude is assumed, therefore making the longitude a positive number. Each transect has two points, a beginning point (1) and an ending point (2). The beginning point represents the starting point for the transect. The ending point represents the end of the transect and should be located closest to the shoreline.

4. Running FINALIZE. Double click on the FINALIZE icon. The SDF FINALIZE window will appear (Figure 28). The user then selects the SDF list, tide data, and output filenames using the browse button (direct typed entry will not work). To include the distance along the transect and the cross track error in the output file, check the Include the Distance Along the Transect and the Cross Track Error box and select the waypoint coordinate file using the browse button. Then select the Datum, State, and the Zone for the State Plane projection. The Zone list is populated based on the selections made in the Datum and State boxes. This computation is embedded in FINALIZE using the commercially available code ProLat.dll, version 3.01, by Effective Objects (http://www.effectiveobjects.com), which uses USGS computational methods. If the combination of Datum, State, and Zone do not correctly match, Zone will appear in the selection box and users will not be able to initiate the program. In these cases, clicking Create Output File of Corrected Data will initiate the program. If invalid data have been entered, the button will be deactivated until correct data have been entered. Status of the program, including any errors, will be noted within the Program Status window.

5. Output file format. The output is in an ASCII comma-delimited (.CSV) format. Figure 29 is an example. Table 3 defines variables contained in this file.

6. Further processing. Some users may find it useful to generate additional summary variables based on the outputs provided. One such variable is Biovolume. This is defined as the portion (percentage) of the water column occupied by vegetation and is computed as:

Biovolume $=$ acoustic_percent_cover * Height_m/Depth_bottom 
Figure 28. FINALIZE graphic user interface window after executing program.

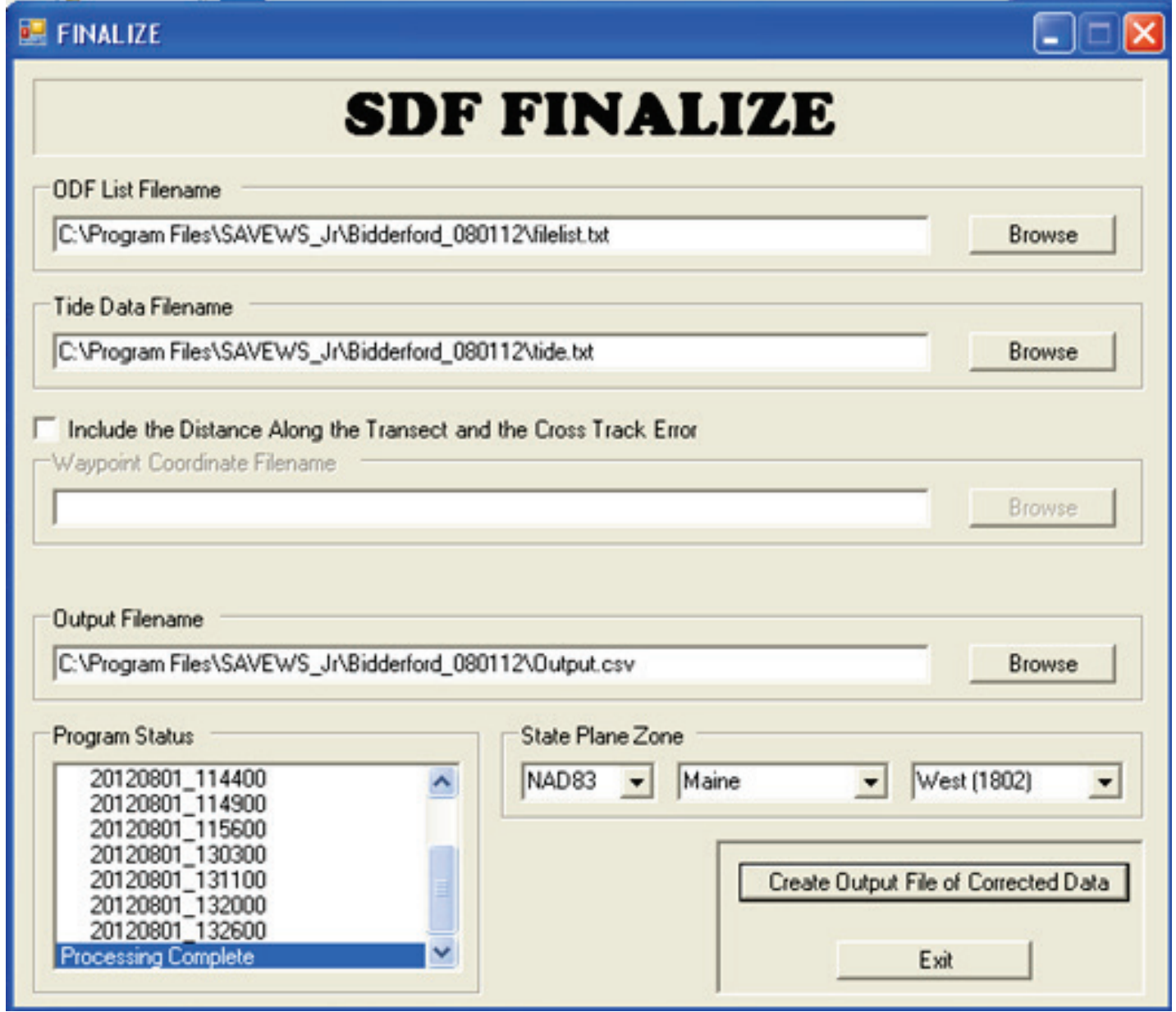


Figure 29. Example output of FINALIZE program (Output.CSV).

\begin{tabular}{|c|c|c|c|c|c|c|c|c|c|c|c|}
\hline Lon & Lat & X_stpln & Y_stpln & Year & Day & Time & Trans & Bottom & Depth_Canopy & Cover & Height_m \\
\hline 70.35202 & 43.45018 & 2903529 & 224880 & 2012 & 214 & 11.6671 & 1 & -3.93 & -3.5 & 66.67 & 0.43 \\
\hline 70.35203 & 43.45021 & 2903526 & 224889 & 2012 & 214 & 11.6675 & 1 & -4.79 & -4.16 & 73.33 & 0.63 \\
\hline 70.35204 & 43.45023 & 2903524 & 224898 & 2012 & 214 & 11.6679 & 1 & -5.42 & -5.42 & 0 & 0 \\
\hline 70.35205 & 43.45026 & 2903521 & 224907 & 2012 & 214 & 11.6684 & 1 & -5.51 & -5.51 & 0 & 0 \\
\hline 70.35206 & 43.45029 & 2903519 & 224918 & 2012 & 214 & 11.6688 & 1 & -5.5 & -5.5 & 0 & 0 \\
\hline 70.35207 & 43.45032 & 2903517 & 224929 & 2012 & 214 & 11.6693 & 1 & -5.52 & -5.23 & 13.33 & 0.29 \\
\hline 70.35208 & 43.45035 & 2903514 & 224940 & 2012 & 214 & 11.6698 & 1 & -5.39 & -5.39 & 0 & 0 \\
\hline 70.35209 & 43.45038 & 2903512 & 224950 & 2012 & 214 & 11.6702 & 1 & -5.33 & -5.33 & 0 & 0 \\
\hline 70.35209 & 43.4504 & 2903510 & 224960 & 2012 & 214 & 11.6707 & 1 & -5.32 & -5.32 & 0 & 0 \\
\hline 70.35211 & 43.45043 & 2903506 & 224971 & 2012 & 214 & 11.6711 & 1 & -5.3 & -5.3 & 0 & 0 \\
\hline 70.35212 & 43.45046 & 2903502 & 224981 & 2012 & 214 & 11.6716 & 1 & -5.15 & -5.15 & 0 & 0 \\
\hline 70.35213 & 43.45049 & 2903499 & 224991 & 2012 & 214 & 11.672 & 1 & -5.13 & -5.13 & 0 & 0 \\
\hline 70.35215 & 43.45051 & 2903495 & 225001 & 2012 & 214 & 11.6724 & 1 & -5.08 & -5.08 & 0 & 0 \\
\hline 70.35216 & 43.45054 & 2903492 & 225009 & 2012 & 214 & 11.6729 & 1 & -5.04 & -5.04 & 0 & 0 \\
\hline 70.35218 & 43.45056 & 2903488 & 225018 & 2012 & 214 & 11.6733 & 1 & -4.86 & -4.86 & 0 & 0 \\
\hline 70.35219 & 43.45059 & 2903485 & 225027 & 2012 & 214 & 11.6737 & 1 & -4.75 & -4.75 & 0 & 0 \\
\hline 70.3522 & 43.45061 & 2903481 & 225036 & 2012 & 214 & 11.6741 & 1 & -4.71 & -4.71 & 0 & 0 \\
\hline 70.35221 & 43.45063 & 2903479 & 225045 & 2012 & 214 & 11.6745 & 1 & -4.59 & -4.59 & 0 & 0 \\
\hline 70.35222 & 43.45066 & 2903475 & 225053 & 2012 & 214 & 11.6749 & 1 & -4.43 & -4.59 & 0 & 0 \\
\hline 70.35224 & 43.45068 & 2903472 & 225063 & 2012 & 214 & 11.6754 & 1 & -4.21 & -4.21 & 0 & 0 \\
\hline 70.35225 & 43.45071 & 2903468 & 225072 & 2012 & 214 & 11.6758 & 1 & -4.04 & -4.04 & 0 & 0 \\
\hline 70.35227 & 43.45073 & 2903464 & 225080 & 2012 & 214 & 11.6762 & 1 & -3.96 & -3.96 & 0 & 0 \\
\hline 70.35228 & 43.45076 & 2903461 & 225090 & 2012 & 214 & 11.6766 & 1 & -3.89 & -3.4 & 20 & 0.49 \\
\hline 70.35229 & 43.45078 & 2903457 & 225098 & 2012 & 214 & 11.677 & 1 & -3.81 & -3.41 & 40 & 0.4 \\
\hline 70.35231 & 43.45081 & 2903454 & 225108 & 2012 & 214 & 11.6774 & 1 & -3.8 & -3.38 & 93.33 & 0.42 \\
\hline
\end{tabular}

Table 3. Definition of output variables from FINALIZE program.

\begin{tabular}{|c|c|c|}
\hline Variable name & Units & Definition \\
\hline Lon & \multirow{2}{*}{$\begin{array}{l}\text { decimal } \\
\text { degrees }\end{array}$} & \multirow[t]{2}{*}{ Geographic coordinates in selected datum } \\
\hline Lat & & \\
\hline X-stpln & \multirow[t]{2}{*}{ feet } & Easting in state plane coordinates \\
\hline Y-stpln & & Northing in state plant coordinates \\
\hline Year & \multirow[t]{2}{*}{ integer } & 4-digit year \\
\hline Day & & 3-digit day of year \\
\hline Time & hours & Local time, 24-hr clock \\
\hline Transect & integer & Transect number \\
\hline Depth_Bottom & \multirow[t]{2}{*}{ meters } & $\begin{array}{l}\text { Distance between water surface and detected bottom (corrected } \\
\text { for transducer depth and tides) }\end{array}$ \\
\hline Depth_Canopy_Bottom & & $\begin{array}{l}\text { Distance between water surface and first object (contiguous with } \\
\text { detected bottom) above threshold (usernoise) }\end{array}$ \\
\hline Acoustic_Percent_Cover & percent & $\begin{array}{l}\text { Estimated coverage, computed as percentage of pings in reporting } \\
\text { cycle in which plants were detected (see Appendix D) }\end{array}$ \\
\hline Height_m & meters & $\begin{array}{l}\text { Average estimated plant height in pings detected with plants in } \\
\text { reporting cycle }\end{array}$ \\
\hline
\end{tabular}




\section{Caveats and Limitations}

The authors are currently aware of a number of performance limitations associated with Version 1.o processing under certain conditions. These known limitations and associated caveats are listed below.

1. Soft, highly absorptive bottom. When a very light bottom, such as floc, or very light organic mud is encountered, the acoustic pulse may be absorbed instead of reflected. When this occurs, no bottom detection will be registered by the algorithm. If SAV is present, the top of the canopy will probably register as the bottom, but SAV will not be declared present. There is currently no approach to handle this situation.

2. Short/low-density SAV. The detection limit for Version 1.0 has not yet been quantitatively established. This is expected to occur as additional ground-truthed data become available. Experience with the original version of SAVEWS showed that detections fell to zero as SAV became shorter and sparser. The computed detection limit for this system was a height of $7 \mathrm{~cm}$ and a density of $60 \mathrm{~g} \mathrm{~m}^{-2}$ (wet weight). Sparse beds of Halodule wrightii were frequently encountered below this detection limit. It is expected that the detection limits for SAVEWS Jr. may be similar.

3. Acoustically impenetrable canopy. When a submerged canopy is so dense that all acoustic energy is reflected from it, no energy is left to reflect from the bottom. When this occurs for many adjoining pings, the top of the canopy will probably be declared to be the bottom and SAV will either not be detected at all or will be mischaracterized. This situation has been observed with very dense Eurasian watermilfoil canopies that form below the surface. These can become colonized with filamentous algae that trap gas, further increasing the acoustic reflectivity of the canopy top. The use of dual frequencies within the current code greatly reduces this occurrence; however, it will still occur under very dense canopy conditions. A solution for this situation is being worked on that involves subtracting a bathymetric grid from the top-of-canopy depth grid generated by acoustic mapping. Significant differences in depth would indicate the presence of plants. The bathymetric grid may be obtained from a separate data source, or it may be generated by acoustic mapping during a period of minimum SAV biomass.

4. Species discrimination. The algorithm generates data that characterized SAV canopy geometry. There is currently no general 
capability to discriminate SAV species or even general classes of SAV. There are, however, a number of specific conditions when limited discrimination is possible. When species present in a body of water are known and there are large differences in characteristics measured by the acoustic system (height for instance), then discrimination is possible. A height discriminator was used to demonstrate the ability to differentiate eelgrass (Zostera marina) from marine macroalgae in a New England estuary during summer. ${ }^{1}$

5. Debris in bottom. The signal processor detects SAV by looking for a contiguous signal above and connected to the bottom. Many things other than SAV can cause such a signal. Sunken debris, branches, and drowned trees can generate an acoustic signal that is indistinguishable from SAV. The proper way of assessing the accuracy of the processor output is with a statistically sound ground-truth sampling effort, which is not covered in this document. One means of mitigating false SAV detections due to debris is to set the maxplantdepth variable in the configuration file to the observed maximum depth of plant growth. This will disallow detection of plant-like signatures at depths too deep to be plants.

6. Rocky irregular bottom. The bottom tracker within the algorithm makes the assumption that the depth of the true bottom changes very little between adjoining pings. This is true for virtually all sediment bottoms. When the bottom consists of large rocks and cobbles, it becomes irregular and this assumption is violated, resulting in incorrect bottom tracking. A separate algorithm is being developed to handle this situation; it will be incorporated into a subsequent version of SAVEWS Jr.

7. Boat wakes and choppy water. Boat propellers, breaking waves, and choppy water act to incorporate small bubbles into the water column. These bubbles are very reflective acoustically and can exceed thresholds used within the algorithm (usernoise). This can lead to false or missed SAV detections. It is best to avoid boat wakes (particularly your own) when executing survey transects, and if conditions get too choppy, it is best to suspend operations until calmer conditions occur.

8. Topped vegetation. The software is designed to detect bottom-attached vegetation that has not reached the surface. The algorithm looks for a zone of "quiet water" with echo intensity below usernoise that is at least mingap meters in depth between startdepth and the first detected returns above usernoise. If this condition is not found, the ping data are

\footnotetext{
${ }^{1}$ Sabol, B. E. Lord, K. Reine, and D. Shafer. 2008. Comparison of acoustic and aerial photographic methods for quantifying the distribution of submersed aquatic vegetation in Sagamore Creek, $\mathrm{NH}$, report ERDC TN-DOER-E23. U. S. Army Engineer Research and Development Center, Vicksburg, MS.
} 
declared to be noisy (i.e. bad) and not output. If the percentage of pings in a report cycle is below the required_good value, then output of that report cycle is suppressed. If working in near-topped vegetation, careful setting of these parameters may allow the output of some or all of these ping samples.

9. Final caveat - VERIFY OUTPUT. If the software described here declares that vegetation of a certain density and height is detected, this only indicates that the acoustic returns are consistent with a scenario where the unknown source of the echoes is submersed vegetation of that particular density and height. Conversely, if output declares a location to be unvegetated, this is only an indication that no signals consistent with submersed vegetation were detected. Vegetation may be present, but at a level below the detection limit of the echo sounder, or at a level below the detection settings of the configuration file. Output should always be verified with at least a limited ground truth sampling or observation effort. 


\section{Point of Contact}

The authors appreciate and welcome feedback and comments from users that will help to identify needed improvements to the code. Point of contact is as follows:

\section{Eddie Melton}

Computer Systems Analyst, JAYA Corporation

US Army Engineer Research and Development Center 3909 Halls Ferry Rd.

Vicksburg, MS 39180

O: 601-634-3498

Eddie.Melton@usace.army.mil

To send files over $8 \mathrm{Mb}$ in size, please use the AMRDEC/SAFE utility:

(https://safe.amrdec.army.mil/SAFE2/). 


\section{References}

Heidelbaugh, W.S., and W. G. Nelson 1991. A power analysis of methods for assessment of change in seagrasscover. Aquatic Botany 53: 227-233.

Mueller-Dombois, D., and H. Ellenberg. 1974. Aims and methods of vegetation ecology. New York: John Wiley \& Sons, Inc.

Norris, J. G., S. Wyllie-Echeverria, T. Mumford, A. Bailey, and T. Turner. 1997. Estimating basal area coverage of subtidal seagrass beds using underwater videography. Aquatic Botany 58: 269-287.

Sabol, B., R. E. Melton, R. Chamberlain, P. Doering, and K. Haunert. 2002. Evaluation of a digital echo sounder for detection of submersed aquatic vegetation. Estuaries 25(1):133-141. 


\section{Appendix A: Assembling a Self-Contained SAVEWS Jr. Field Unit}

This appendix describes the parts necessary to construct a portable, selfcontained SAVEWS Jr. system. The system described in this section is an example of a functioning and tested system used by the New England District of USACE. Please note that damage to the Lowrance HDS system or LSS2 StructureScan unit resulting from modification of factory components or incorrect wiring procedures is the responsibility of the user. The Lowrance factory wiring diagram provided with the HDS system and appropriate in-line fuses should be used in assembly of the system.

The system (Figure A1) consists of a Lowrance LSS-2 structure scan module and a 12-V DC power source housed in a waterproof case (Figure A2), a quick disconnect swivel mount for the HDS unit, and a waterproof throughdeck fitting for transducer and power connections (Figure A3). The system includes provisions for external power through the use of a $12-\mathrm{V}$ waterresistant male trolling motor socket built into the case (Figure A4), which is paired with female trolling motor plug-wired ring terminals to receive power from an external 12-V battery. The pictured system also includes a male serial connector wired to the NMEA output on the HDS power/data cable. The transducers (455/800-KHz StructureScan and 200-kHz skimmer) and external GPS antenna are mounted to an adjustable bracket (Figures A5 and A6), which clamps on to the bow or rail of the survey vessel. The external GPS antenna (not pictured) should be mounted to a pole that can be clamped to the transducer bracket. This allows the user to overlay position data on a paired video system recording in real time or to another external source. A parts list for the example system is provided in Table A1. 
Figure A1. Portable SAVEWS Jr. System.

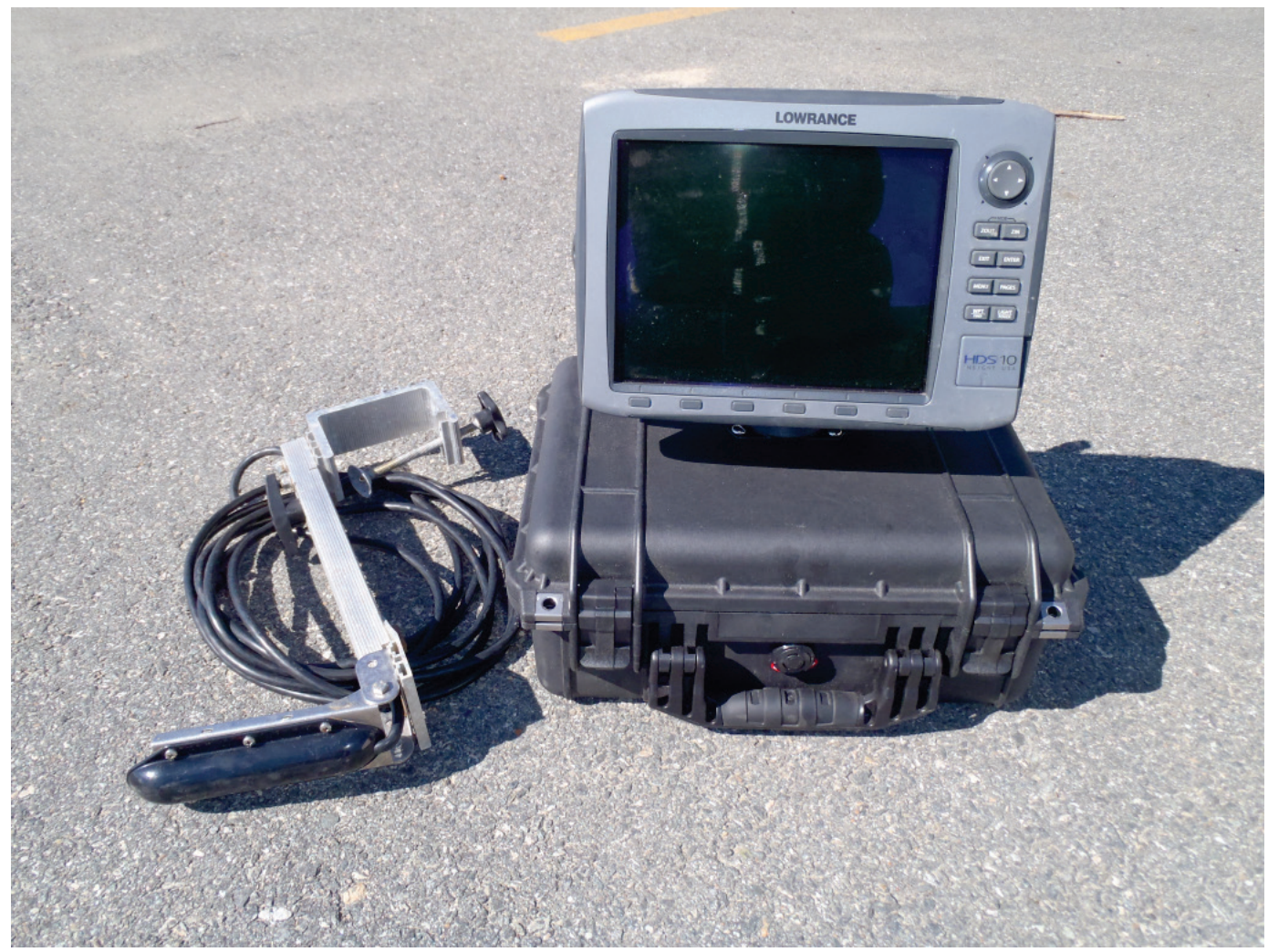

Figure A2. LSS-2, 12-V power source and wiring.

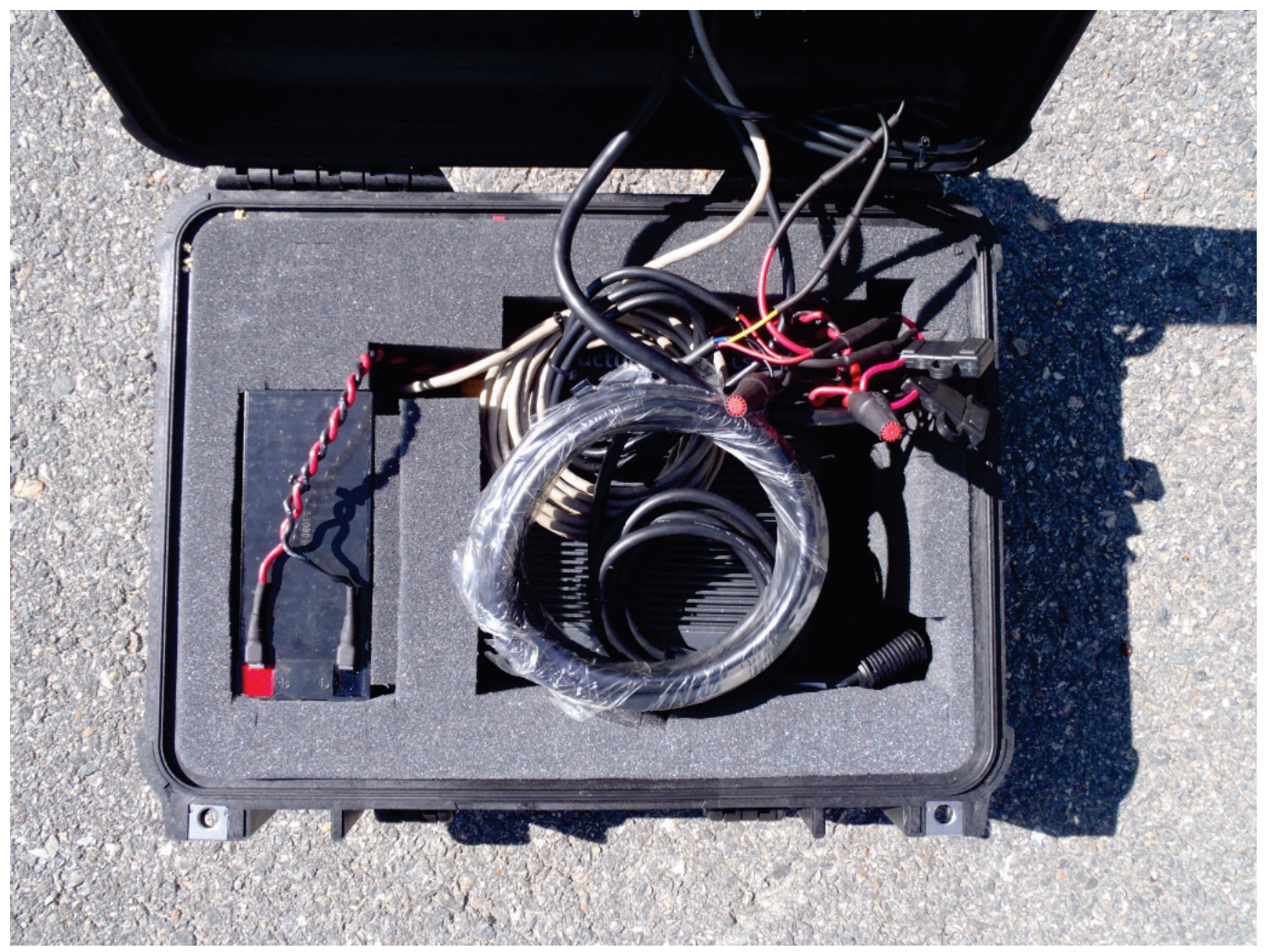


Figure A3. Quick disconnect mount external connections.

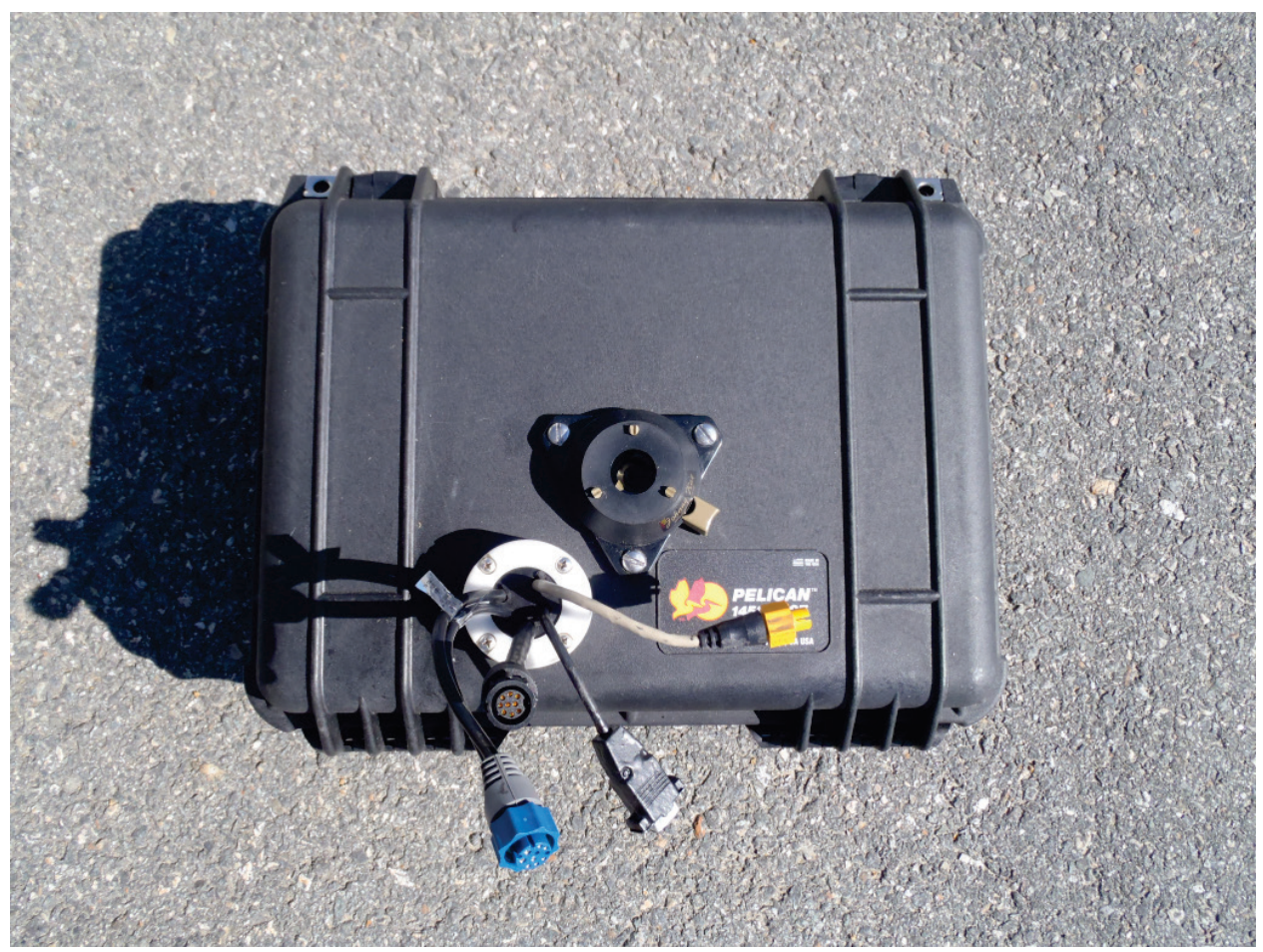

Figure A4. External power connection.

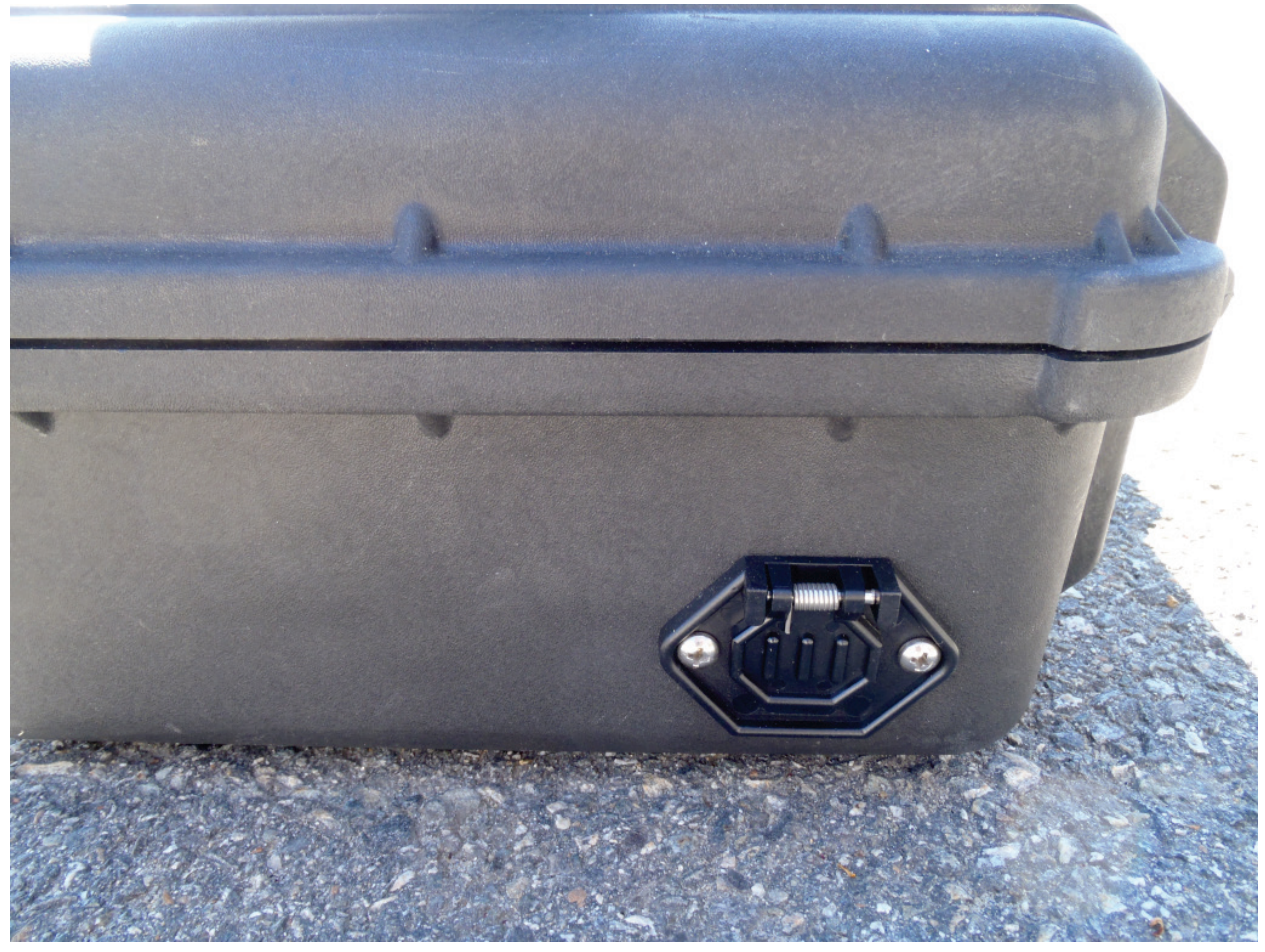


Figure A5. Transducers, mounted on pivot arm, and GPS antenna mounting bracket.

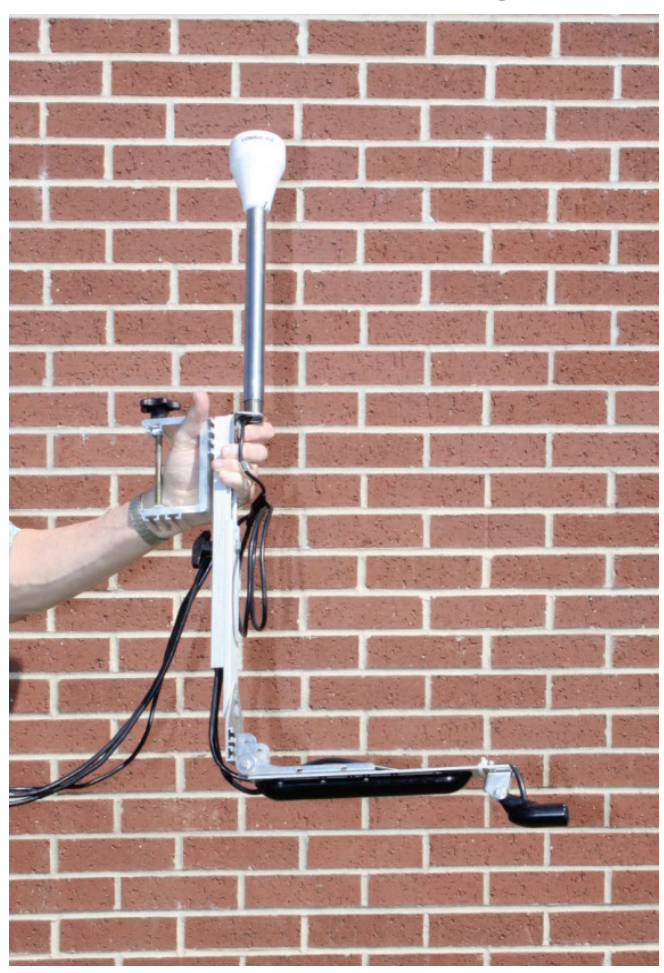

Figure A6. Transducer and GPS bracket in use.

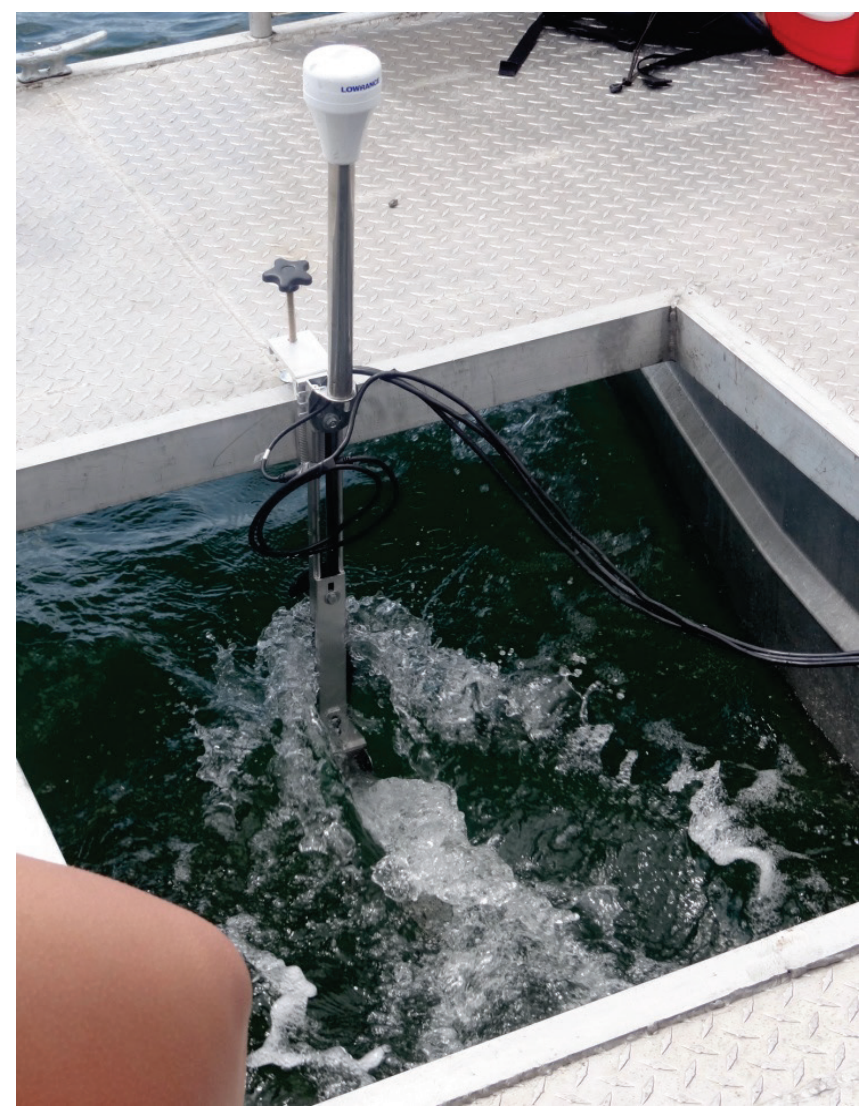


Table A1. Components of example self-contained SAVEWS Jr. system

\begin{tabular}{|c|c|c|}
\hline Component & Description & Part \# \\
\hline $\begin{array}{l}\text { Integrated echo sounder } \\
\text { with internal GPS system }\end{array}$ & $\begin{array}{l}\text { Lowrance HDS-10 with } 50 / 200 \mathrm{kHz} \\
\text { skimmer transducer }\end{array}$ & Lowrance 000-0140-02 \\
\hline $\begin{array}{l}\text { Structure Scan module } \\
\text { and transducer }\end{array}$ & $\begin{array}{l}\text { Lowrance LSS-2 Structure Scan module for } \\
\text { HDS systems with } 455 / 800 \mathrm{kHz} \\
\text { transducer }\end{array}$ & Lowrance 000-0132-06 \\
\hline $\begin{array}{l}\text { Structure Scan transducer } \\
\text { extension cable }\end{array}$ & $\begin{array}{l}\text { Lowrance extension cable for LSS-2 } \\
\text { transducer }\end{array}$ & Lowrance 99-006 \\
\hline External GPS & $\begin{array}{l}\text { Lowrance LGC- } 4000 \text { high sensitivity GPS } \\
\text { receiver antenna }\end{array}$ & Lowrance 000-0125-28 \\
\hline NMEA 2000 network & Lowrance NMEA 2000 network & N2K-EXP-RD-2 \\
\hline Waterproof case & $\begin{array}{l}\text { Pelican Case } 1450 \text { with Pick 'N Pluck Foam } \\
\text { Case }\end{array}$ & Pelican 1450 \\
\hline $\begin{array}{l}\text { Removable mount for } \\
\text { HDS unit }\end{array}$ & $\begin{array}{l}\text { Johnny Ray swivel mount for electronic } \\
\text { instruments with push-button release }\end{array}$ & Jonny Ray JR-300 \\
\hline $\begin{array}{l}\text { Waterproof through-deck } \\
\text { fitting }\end{array}$ & Large CableClam waterproof fitting & Blue Sea Systems 1003 \\
\hline $\begin{array}{l}\text { Adjustable transducer } \\
\text { mounting bracket }\end{array}$ & $\begin{array}{l}\text { Sully transducer mounting bracket for } \\
\text { pontoon and thick-transom boats (selected } \\
\text { for versatility) }\end{array}$ & Sully $8001 \mathrm{P}$ \\
\hline Internal power source & 12-V/7.5-Amp rechargeable battery & NA \\
\hline $\begin{array}{l}\text { Optional } 12-V \text { external } \\
\text { power connection }\end{array}$ & $\begin{array}{l}\text { 12-V 2-wire trolling motor connectors } \\
\text {-male boat side socket (case) } \\
\text {-female plug (wire with ring terminals or } \\
\text { alligator clips to external battery) }\end{array}$ & $\begin{array}{l}\text { Sierra WH10520 (male) } \\
\text { WH10530 (female) }\end{array}$ \\
\hline $\begin{array}{l}\text { Power switch for running } \\
\text { the HDS unit without the } \\
\text { LSS-1 module }\end{array}$ & $\begin{array}{l}\text { Chrome-plated } 12-V \text { DC SPST toggle switch } \\
\text { with water-resistant switch boot }\end{array}$ & NA \\
\hline
\end{tabular}

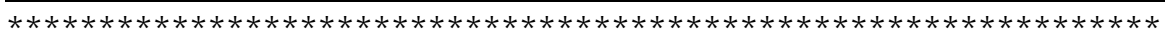

For questions, please contact:

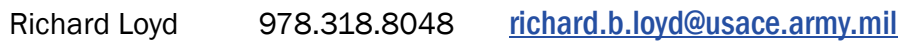

$* * * * * * * * * * * * * * * * * * * * * * * * * * * * * * * * * * * * * * * * * * * * * * * * * * * * * * * * * * * * * * *$ 


\section{Appendix B: Configuration File -DEFAULT.sjrcfg}

Configuration file testing in May 2012; Cutty Hunk data collected by Ben Loyd; file created $07 / 19 / 12$

The values for the parameters in this file may be edited.

WARNING! CHANGING ANYTHING OTHER THAN THE NUMERIC VALUES FOR THE PARAMETERS WILL CAUSE THE CONFIGURATION FILE TO BECOME INVALID!

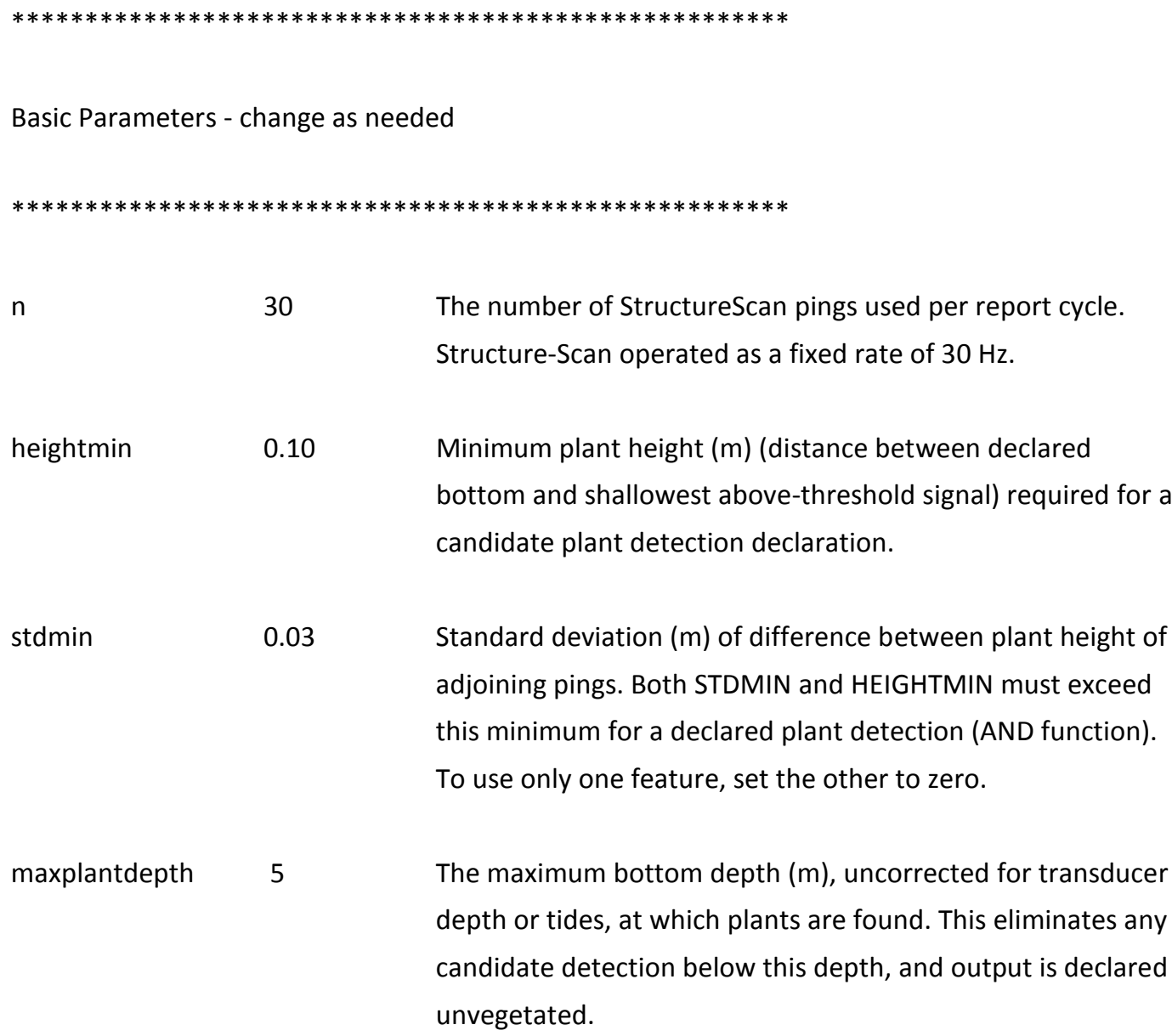

$\mathrm{n}$

30

heightmin

0.10

stdmin

0.03

maxplantdepth

5

The maximum bottom depth $(\mathrm{m})$, uncorrected for transducer depth or tides, at which plants are found. This eliminates any candidate detection below this depth, and output is declared unvegetated. 


\begin{abstract}
$* * * * * * * * * * * * * * * * * * * * * * * * * * * * * * * * * * * * * * * * * * * * * * * * * * * * *$
Intermediate Parameters - change with caution

$* * * * * * * * * * * * * * * * * * * * * * * * * * * * * * * * * * * * * * * * * * * * * * * * * * * * *$

$\begin{array}{lll}\text { startdepth } & 0.5 & \text { The depth }(\mathrm{m}) \text { below transducer (zero depth) to start }\end{array}$ processing. This value can be set higher if it is necessary to read past an interference such as reflection from the motor's lower unit. All data prior to this depth are ignored.

usernoise

0

Setting this value to zero will activate automated determination of the noise threshold using the percentile value below. If set to a non-zero value, that number will be used as the noise threshold value.

percentile

75

The percentile of program-generated noise threshold data to be represented by the program-determined overall noise threshold. Higher percentile values result in higher thresholds, with less sensitivity to noise and plant detection.

mingap

The minimum quiet zone distance $(\mathrm{m})$ that must be below the noise threshold in order to detect vegetation. If this quiet zone minimum is not met, the ping is rejected as bad data.

Only decrease this value below $0.10 \mathrm{~m}$ if working in extremely shallow water or inherently "noisy" water. In this situation, an alternate approach would be to increase the usernoise value.

bot_med_filt_size $9 \quad$ Parameter for smoothing bottom declarations. The value represents the number of elements used in a median filter. Use only odd numbers between 5 and 13.

bot_change_tol 10

Parameter for smoothing bottom declarations. If deviation $(\mathrm{m})$ between current value and the median determined by median filter of size. bot_med_filt_size exceeds this value, then the current value will be replaced by the median. Deactivate this feature by setting it to a very large value, such as $10 \mathrm{~m}$.
\end{abstract}




\begin{abstract}
cand_veg_amt 5 The minimum percentage of pings in a report cycle that must be candidate vegetation before output is declared to be vegetation. If this percentage is not met, the report is declared unvegetated.

required_good $\quad 30 \quad$ Minimum percentage of pings in report cycle (set as $\mathrm{n}$ above) that must be valid data before that report cycle is output (30 is considered the minimum recommended value).
\end{abstract}

\begin{abstract}
$* * * * * * * * * * * * * * * * * * * * * * * * * * * * * * * * * * * * * * * * * * * * * * * * * * * * *$
Advanced Parameters - recommend not changing

swin

9

th_limit

230

use_all

1

The width of the median filter to be used in smoothing the pings. If changing this parameter, refer to filterflag in the "Intermediate Parameters" section to complete parameter setup.

The maximum allowable noise threshold for a ping.

Set this value to 1 for all data to be used, or 0 for only half of the data (depth-wise) to be used. This is a data reduction option that achieves processing time cost savings if the depth recording value is $>2 x$ bottom depth.
\end{abstract}

hist_width

0.02 bot_wid_percent 1

filterflag

The width $(\mathrm{m})$ of the bins to use in the histogram analysis that results in bottom declarations. This value represents the bin widths into which bottom candidates are placed in order to make accurate bottom declarations.

The percentage of bottom widths that can have a width of 0 . This is used to set the threshold value to calculate the width of the bottom. The threshold value is increased until (bot_wid_percent) percent of pings have no bottom width. Set this value to 1 if median filtering of the original ping data is desired, or 0 if median filtering is NOT desired. For 200-khz input data, this filtering must always be used. If using median 
filtering, refer to "swin" in the "Advanced Parameters" section.

For questions, please contact:

Bruce Sabol 601.634 .2297 bruce.m.sabol@erdc.dren.mil

Eddie Melton 601.634.3498 eddie.melton@usace.army.mil

If sending files to troubleshoot, always send the .SJRCFG file used. 


\section{Appendix C: Suggested Field Datasheet}


Date

Location

Operator

Tide data source

Equipment ID \#
Vessel

Crew

Transducer mount location

Transducer depth (m)

\begin{tabular}{|c|c|c|c|c|}
\hline \multirow[t]{2}{*}{ HDS filename } & \multicolumn{2}{|c|}{ Recording time } & \multirow[t]{2}{*}{ Final filename } & \multirow[t]{2}{*}{ Note } \\
\hline & Start & Stop & & \\
\hline & & & & \\
\hline & & & & \\
\hline & & & & \\
\hline & & & & \\
\hline & & & & \\
\hline & & & & \\
\hline & & & & \\
\hline & & & & \\
\hline & & & & \\
\hline & & & & \\
\hline & & & & \\
\hline & & & & \\
\hline & & & & \\
\hline
\end{tabular}




\section{Appendix D: Description of Acoustic Percent Coverage}

Percent coverage is a widely used quantitative metric to characterize plant stands, both terrestrial and aquatic. Measurements of plant percent cover may be more ecologically meaningful than numbers of individuals, since cover is likely to provide a better measure of plant biomass than abundance (Mueller-Dombois and Ellenberg 1974). Visual estimates of seagrass percent cover using quadrats has been shown to require fewer replicates and less sampling effort for detecting differences than estimates of shoot count or biomass, making percent cover estimates more cost effective (Heidelbaugh and Nelson 1991). However, it is not practical to sample large areas using this technique. Alternatively, underwater videography has also been used to estimate seagrass basal area coverage over larger areas, but these methods are limited to areas with good water clarity (Norris et al. 1997). Both quadrat and underwater videography methods involve imposing a frame of a known size over the bottom, followed by estimating the proportion of the surface area within the frame that is occupied by vegetation.

In some ways, the acoustic technique presented here is analogous to a series of visual estimates of percent cover. For example, each individual sample (single ping) of the SAVEWS Jr. system could be likened to a small quadrat; SAVEWS Jr. transects would thus be similar to a series of contiguous small quadrats arranged in a belt transect. In this case, overall seagrass cover within the area occupied by the belt transect would be computed as the average cover of all quadrats within that transect, and as pointed out by Mueller-Dombois and Ellenberg (1974), continuous transects of evenly spaced points should result in more accurate estimates of plant cover than random placements of grouped points. However, the way in which seagrass cover is detected and estimated in the hydroacoustic technique is fundamentally different. In the visual methods, the percent cover of seagrass within each quadrat is estimated as the proportion of the bottom that is covered by vegetation. In contrast, the acoustic technique classifies each individual sample (single ping) as either detecting or not detecting SAV. The requirement for detection is that acoustically reflective material occurs contiguously above the bottom for some minimum distance. As noted in this manual, the sensitivity of the acoustic echo and 
minimum distance above the bottom required for detection can both be set by the user to be more or less sensitive, based on conditions and survey objectives. Coverage is then estimated as the percentage of pings within a localized area (settable as a reporting cycle using parameter $\boldsymbol{N}$ in $\mathrm{CF}$, see Appendix B). Each ping within the reporting cycle either represents a detection or it does not (binary). While this seems a reasonable approach given the constraints of the acoustic system, it is a fundamentally different measure from the physical and visual measured. For this reason, this measure has been labeled as Acoustic Percent Coverage. The resulting acoustic percent coverage summarizes results from a linear string of binary detection samples.

This is illustrated below, along with an example of the calculations for coverage and mean height (Figure D1).

Figure D1. Acoustic survey cartoon and computation of outputs using 10 pings per report cycle.

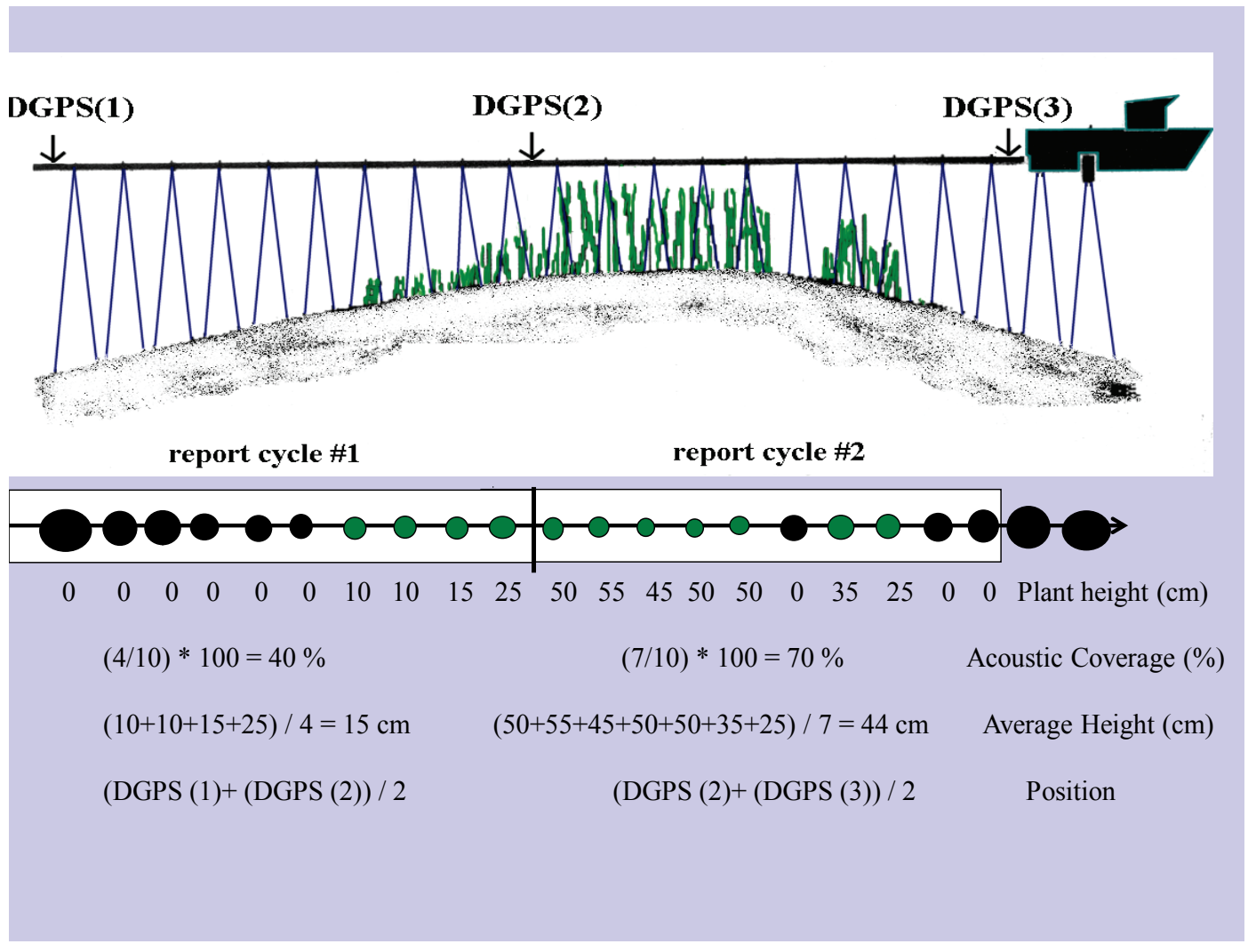

The flexibility in setting processing parameters, the binary nature of detection, and the fact that there will always be an inherent (and variable) detection limit makes acoustic coverage different from the standard coverage measure. This is illustrated in the hypothetical example below 
(Figure D2). A 2.5-m segment is acoustically surveyed (1 second at 5 knots boat speed and 30 pings/sec) and sampled by a diver. Depth is assumed to be approximately $1.6 \mathrm{~m}$; thus, the acoustic area sampled has a diameter of approximately $8 \mathrm{~cm}$ (roughly $5 \%$ of depth for an $800-\mathrm{kHz}$, downwardfacing channel) so that the sampled circles are almost contiguous (30 $\mathrm{x}$ $0.08 \mathrm{~m}=2.4 \mathrm{~m}$ ). Diver measurements (quadrat coverage and plant height) for 10 contiguous $0.25-\mathrm{m}$ quadrats show an average coverage of $50 \%$ and an average plant height of $13 \mathrm{~cm}$. Acoustic data are processed with three levels of sensitivity, controlled by the sensitivity threshold usernoise and the height threshold heightmin. This example assumes that adjustments of these thresholds translate to the following detection performance.

1. Highest sensitivity: plant height $>5 \mathrm{~cm}$ and coverage $>15 \%$;

2. Intermediate sensitivity: plant height $>10 \mathrm{~cm}$ and coverage $>20 \%$;

3. Lowest sensitivity: plant height $>15 \mathrm{~cm}$ and coverage $>25 \%$.

Corresponding detection performance for the acoustic survey with the diver survey shows general agreement but also illustrates the effect of user-defined sensitivity (for purposes of graphic simplicity, acoustic detection is only shown for every third ping).

Figure D2. Hypothetical comparison of diver and acoustic measurements for a 2.5-m linear segment of SAV.

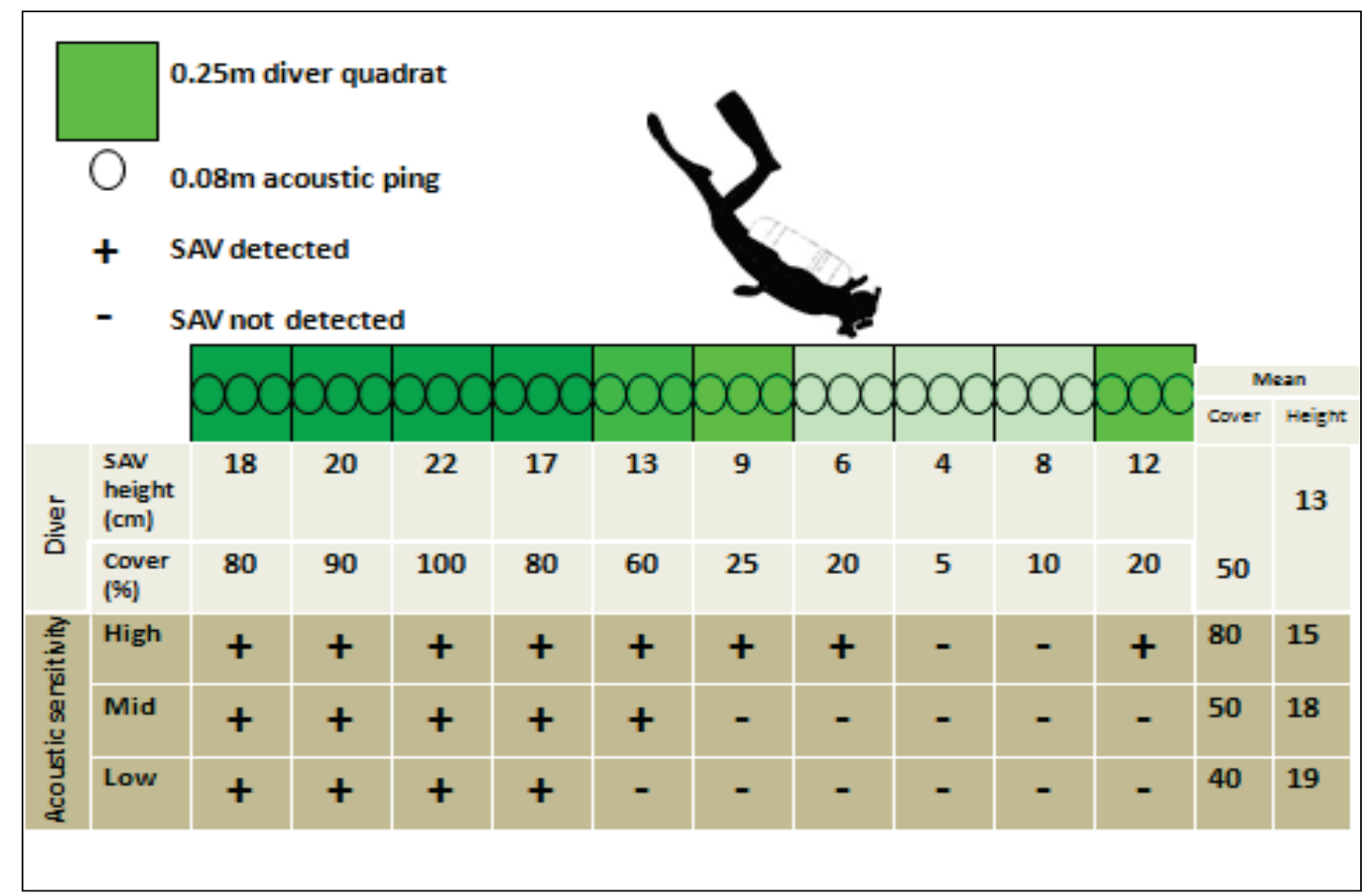


One could easily envision scenarios where there are dramatic differences between diver and acoustic survey technique results. An example of this would be surveys in sparse vegetation below the detection limit of the acoustic system - such as sparse and short Halodule spp. or Halophila spp. When operating in vegetation within the performance bounds of the acoustic system, results have been found to be generally similar.

Simultaneous diver and acoustic data have been collected and analyzed for SAVEWS (Figure D3); however, this has not yet occurred for the SAVEWS Jr. system. The data in Figure D3 compare SAVEWS with simultaneous interpreted underwater video for a southwest Florida site containing a mixed bed of Halodule, Syringodium, and Thallasia (Sabol et al. 2002). The acoustic system was found to generate coverage estimates that were highly correlated, but slightly below, that of the videographic technique; there was, however, very good agreement on boundaries. While similar validation data are not yet available for the SAVEWS Jr. system, simultaneous comparisons with the SAVEWS system found a high level of agreement. SAVEWS Jr. is expected to exhibit a level of agreement that is at least similar to the standard SAVEWS coverage measures.

Figure D3. Comparison of interpreted underwater videography and SAVEWS acoustic system in a mixed seagrass bed in southwest Florida.

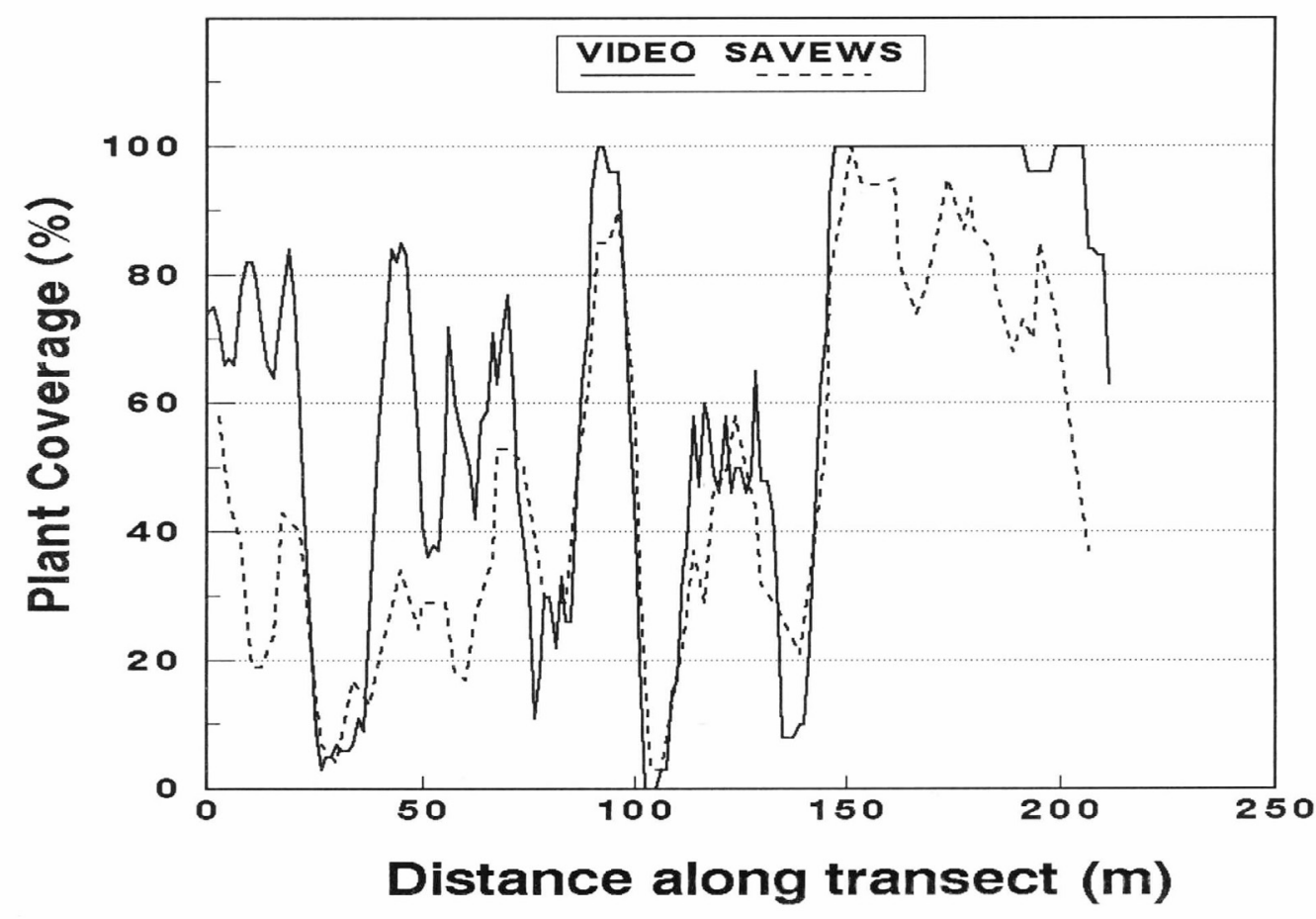




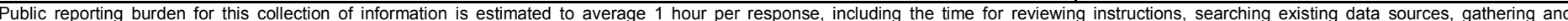

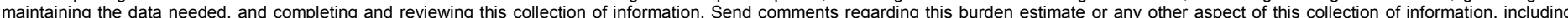

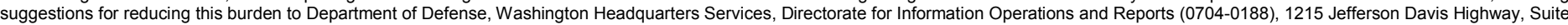

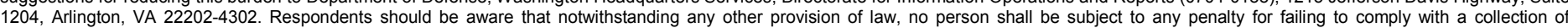
information if it does not display a currently valid OMB control number. PLEASE DO NOT RETURN YOUR FORM TO THE ABOVE ADDRESS.
1. REPORT DATE (DD-MM-YYYY) 2. REPORT TYPE
April 2014 Final report
3. DATES COVERED (From - To)

\section{TITLE AND SUBTITLE}

SAVEWS Jr. User's Manual, Version 1.0

5a. CONTRACT NUMBER

\section{AUTHOR(S)}

Bruce Sabol, Eddie Melton, Deborah Shafer, Jessie Jarvis, and Steve Evert

5b. GRANT NUMBER

5c. PROGRAM ELEMENT NUMBER

5d. PROJECT NUMBER

5e. TASK NUMBER

5f. WORK UNIT NUMBER

\section{PERFORMING ORGANIZATION NAME(S) AND ADDRESS(ES)}

8. PERFORMING ORGANIZATION REPORT NUMBER

Environmental Laboratory

US Army Engineer Research and Development Center

ERDC/EL TR-14-8

3909 Halls Ferry Road, Vicksburg, MS 39180-6199;

JAYA Corporation

4845 University Square, Suite 9

Huntsville, AL 35816;

Richard Stockton College

101 Vera King Ferris Drive, Galloway, NJ 08205-9441;

US Army Engineer District, New England

696 Virginia Road, Concord, MA 01742-2718

9. SPONSORING / MONITORING AGENCY NAME(S) AND ADDRESS(ES)

10. SPONSOR/MONITOR'S ACRONYM(S)

Headquarters, U.S. Army Corps of Engineers

Washington, DC 20314-1000

11. SPONSOR/MONITOR'S REPORT NUMBER(S)

\section{DISTRIBUTION / AVAILABILITY STATEMENT}

Approved for public release; distribution unlimited.

\section{SUPPLEMENTARY NOTES}

\section{ABSTRACT}

This user's manual describes components, assembly, system configuration, data collection procedures, and data processing activities for the second iteration of the Submersed Aquatic Vegetation (SAV) Early Warning System (SAVEWS Jr.). SAVEWS Jr. uses two frequencies (200- and 800-kHz) from a downward-aimed echo sounder to determine the bottom depth and presence/absence of SAV. If SAV is present, canopy height and vegetation percent coverage are estimated. Once collected, the digital data (Lowrance proprietary .SL2 files) are displayed, using the SAVEWS Jr. software. Users then select a configuration file that is appropriate to the environment sampled. A general version of this file is provided with the installation software to serve as a starting point for users to develop their own customized files.

After initial processing, a display of classified output (bottom depth and canopy top) is superimposed on the colorized echogram and aligned with data plots of canopy height and percent coverage. Beyond quality assurance graphics, the primary output of SAVEWS Jr. is the .SDF file (SAVEWS data file) which is an ASCII, comma-delimited file containing position-referenced classified output. This can be used directly in statistical analyses or mapping software.

\begin{tabular}{ll}
\hline 15. SUBJECT TERMS & SAVEWS Jr. \\
Aquatic plant control & Submersed aquatic vegetation (SAV)
\end{tabular}

SAVEWS

16. SECURITY CLASSIFICATION OF:

\section{a. REPORT}

UNCLASSIFIED b. ABSTRACT

UNCLASSIFIED c. THIS PAGE

UNCLASSIFIED

\begin{tabular}{l|c|} 
17. LIMITATION & $\begin{array}{c}\text { 18. NUMBER } \\
\text { OF ABSTRACT }\end{array}$ \\
& 68
\end{tabular}

19a. NAME OF RESPONSIBLE PERSON

19b. TELEPHONE NUMBER (include area code)

Standard Form 298 (Rev. 8-98) 